\title{
Uma heurística para o problema de dimensionamento de lotes em fundições de mercado
}

Viviane Sayuri Tonaki 



\title{
Uma heurística para o problema de dimensionamento de lotes em fundições de mercado ${ }^{1}$
}

\author{
Viviane Sayuri Tonaki
}

\section{Orientadora: Prof ${ }^{a}$ Dr $^{a}$ Franklina Maria Bragion de Toledo}

Dissertação apresentada ao Instituto de Ciências Matemáticas e de Computação - ICMC-USP, como parte dos requisitos para obtenção do título de Mestre em Ciências - Ciências de Computação e Matemática Computacional.

"VERSÃO REVISADA APÓS A DEFESA"

Data da Defesa: 22.05.2006

Visto do orientador:

USP - São Carlos

Novembro/2006

${ }^{1}$ Este trabalho contou com o apoio financeiro do CNPq. 

À minha família. 



\section{Agradecimentos}

- À Deus pela minha vida;

- à minha orientadora Fran pela dedicação, compreensão e amizade;

- aos meus pais Neuza e Paulo, irmãos Fernando e Ronaldo e tios Luiz e Alice pelos conselhos, incentivo, carinho e apoio;

- ao meu namorado Fabio por estar sempre ao meu lado;

- aos professores Marcos e Silvio pelos conselhos que só tiveram contribuições positivas para este trabalho;

- ao Humberto pelo auxílio no estudo de caso;

- ao pessoal da fundição que concederam os dados para a realização deste trabalho e sempre estiveram à disposição para quaisquer esclarecimentos;

- ao João pelo código do algoritmo de programação dinâmica;

- ao pessoal do laboratório pela amizade e por estarem sempre dispostos a ajudar;

- aos professores e funcionários do ICMC que, direta ou indiretamente, contribuíram para a realização deste trabalho;

- aos amigos distantes que sempre estiveram presentes nos momentos difíceis;

- ao $\mathrm{CNPq}$ pelo apoio financeiro para realização desta pesquisa. 



\section{Resumo}

O setor de fundições é importante para a economia, pois produz componentes básicos para muitos outros setores, de modo que seu bom desempenho tem repercussão nos demais. Um modelo de programação inteira mista para uma fundição de mercado de pequeno porte, que visa principalmente minimizar atrasos na entrega dos pedidos, foi proposto na literatura. Neste trabalho é feito um estudo do modelo e é proposta uma nova abordagem, independente de qualquer software comercial, baseada na decomposição do problema em dois subproblemas: o planejamento da produção das ligas e o planejamento da produção dos itens. Ambos foram resolvidos por uma heurística lagrangiana baseada em transferências. Testes computacionais mostraram que a abordagem proposta é capaz de gerar soluções de boa qualidade, em tempo computacional aceitável.

Palavras-chave: Fundição; Dimensionamento de Lotes; Programação Inteira; Heurística. 



\begin{abstract}
The foundry sector is important to the economy as it produces basic components for many other sectors, to such an extent that its performance has a repercussion in other sectors. A recently published mixed integer-programming model for small market-driven foundries, which aims to minimize delays when delivering orders, was proposed in the literature. In this work, a study of this model was undertaken and a new approach is put forward, regardless of any commercial software, based on dealing with the problem in two sub problems: production planning of alloys and production planning of items. Both sub problems were solved by a Lagrangian heuristic based on transfers. Computational tests show that the approach proposed is able to generate solutions of good quality in acceptable computational time.
\end{abstract}

Keywords: Foundry; Lot sizing; Integer Programming; Heuristic. 



\section{Sumário}

1 Revisão bibliográfica 5

1.1 Considerações iniciais . . . . . . . . . . . . . . . . . . . . 5

1.2 O problema de dimensionamento de lotes monoestágio $\ldots \ldots$. . . . . . . 7

1.2.1 Problemas com um único item sem restrições de capacidade . . . . 7

1.2.2 Problemas com múltiplos itens com restrições de capacidade . . . . 9

1.3 Trabalhos específicos no setor de fundições . . . . . . . . . . . . . . 11

2 Descrição do problema abordado $\quad 15$

2.1 Considerações iniciais . . . . . . . . . . . . . . . . . . . . 15

2.2 Descrição do problema . . . . . . . . . . . . . . . . . 15

2.3 Modelagem matemática . . . . . . . . . . . . . . . . 17

3 Abordagem proposta para resolução 21

3.1 Considerações iniciais . . . . . . . . . . . . . . . . . . . . . . . 21

3.2 Problema de definição das ligas . . . . . . . . . . . . . . . . . . . . 21

3.3 Problema de definição dos itens . . . . . . . . . . . . . . . . . 26

3.4 Testes computacionais . . . . . . . . . . . . . . . . . . . . 28

3.4.1 Abordagem sem penalidade para antecipação de liga . . . . . . . 31

3.4.2 Abordagem com penalidade para antecipação de liga . . . . . . . . 38

3.5 Considerações finais . . . . . . . . . . . . . . . . . . . . 45 
4 Uma heurística para o problema $\quad 47$

4.1 Considerações iniciais . . . . . . . . . . . . . . . . . . . . . 47

4.2 Heurística para o Modelo das Ligas . . . . . . . . . . . . . . . . 47

4.2.1 Relaxação lagrangiana . . . . . . . . . . . . . . . . . . . . . . 48

4.2 .2 Heurística lagrangiana . . . . . . . . . . . . . . . . . . . 49

4.3 Heurística para o Modelo das Peças . . . . . . . . . . . . . . . 52

4.3.1 Relaxação lagrangiana . . . . . . . . . . . . . . . . . . 53

4.3 .2 Heurística lagrangiana . . . . . . . . . . . . . . . . . 54

4.4 Aprimoramento proposto . . . . . . . . . . . . . . 55

4.5 Testes computacionais . . . . . . . . . . . . . . . 57

4.5.1 Heurística de decomposição ............ 58

4.5.2 Heurística para o Modelo das Peças . . . . . . . . . . . . . 64

4.5.3 Aprimoramento proposto para a heurística . . . . . . . . . . 65

4.6 Considerações finais . . . . . . . . . . . . . . . . . . . . 70

$\begin{array}{lll}5 & \text { Estudo de caso } & 73\end{array}$

5.1 Considerações iniciais . . . . . . . . . . . . . . . . . . . . . . 73

5.2 Comparação dos resultados . . . . . . . . . . . . . . . . 74

5.3 Considerações finais . . . . . . . . . . . . . . . . . . . 76

$\begin{array}{lll}6 & \text { Conclusões e próximos passos } & 77\end{array}$

Referências bibliográficas $\quad 85$

$\begin{array}{ll}\text { A Requisitos para a heurística desenvolvida } & 87\end{array}$ 


\section{Introdução}

Atualmente, diversos fatores tais como, a alta velocidade de desenvolvimento dos produtos e a crescente globalização dos mercados, fazem com que as empresas enfrentem um ambiente altamente competitivo. Esses fatores levam à busca continua de novas técnicas que permitam atingir elevados índices de eficiência e baixos custos operacionais, o que vem aumentando os investimentos na área de planejamento da produção.

O planejamento da produção é uma atividade que avalia decisões para um melhor uso dos recursos disponíveis, visando satisfazer os objetivos produtivos da empresa sobre um certo período, chamado de horizonte de planejamento. O processo de tomada de decisões pode ser dividido em três níveis: estratégico, tático e operacional (ANTHONY, 1965). O planejamento estratégico está relacionado ao mais alto nível de tomada de decisões, onde são definidas as metas globais da empresa e as políticas adequadas para atingi-las, determinando os objetivos da empresa a longo prazo. O planejamento tático é responsável pela utilização eficiente dos recursos disponíveis, a fim de cumprir os objetivos determinados no planejamento estratégico. Nesta etapa, devem ser tomadas as decisões de médio prazo. O último nível de planejamento é o operacional que está relacionado ao dia-a-dia da empresa, em que são tomadas as decisões de curto prazo.

Este trabalho enfoca o problema de dimensionamento de lotes, que visa estabelecer a quantidade a ser produzida de cada item (ou o tamanho do lote) em cada um dos períodos de um horizonte de planejamento finito. O objetivo é determinar um plano de produção que minimize os custos de produção e de estoque, respeitando os recursos disponíveis e atendendo a uma demanda previamente determinada. Esse problema é 
encontrado em vários setores produtivos, tais como indústrias de alimentos, de bebidas, e também, em fundições. O problema de dimensionamento de lotes, objeto de estudo desta pesquisa, foi inspirado no setor de fundições. Logo, além das características descritas, outra decisão fundamental para o problema é a escolha da liga que será fundida em cada um dos períodos do horizonte de planejamento. Embora na literatura o problema de dimensionamento de lotes se enquadre no planejamento tático da produção, neste trabalho, o problema estudado será uma importante ferramenta de apoio às decisões operacionais da empresa, e, portanto, será utilizado no planejamento tático-operacional da empresa, conforme apresentado em (ARAUJO, 2003).

O setor de fundições é importante para a economia já que, atualmente, está presente em todas as regiões do país, produzindo desde peças simples de uso doméstico, até mais sofisticadas, como autopeças e partes de equipamentos industriais (ARAUJO, 2003). Segundo o relatório da ABIFA (Associação Brasileira de Fundição), em janeiro de 2006 o setor produziu em média 10.785 toneladas/dia, gerando mais de 58.000 empregos diretos. Além disso, o setor continua crescendo, a produção de fundidos em 2005 cresceu 4,8\% em relação à 2004, ano em que o setor registrou um recorde histórico: 25,8\% de crescimento com relação a 2003 (ABIFA, 2006).

Como relatado em (ARAUJO, 2003), existem dois tipos de fundições: cativas e de mercado. As fundições cativas são responsáveis pela grande maioria da produção brasileira de fundidos. São departamentos de grandes empresas cuja produção é destinada, basicamente, para consumo próprio e são orientadas para a produção em série, automatizada, e fabricam grandes quantidades de cada item. Já as fundições de pequeno e médio porte, chamadas fundições de mercado, atendem a demanda de empresas menores, que precisam do produto fundido em quantidades pequenas. Dedicam-se exclusivamente à vendas para terceiros e têm uma carteira de pedidos bastante diversificada. Segundo o autor, a resolução de problemas de planejamento da produção de fundições pequenas pode ser mais difícil do que de grandes fundições. As informações contidas na carteira de pedidos das fundições pequenas, geralmente, envolve um número maior de ligas e peças diferentes, além da grande variação da demanda tanto em relação ao número de itens quanto em relação à quantidade em kg.

Em uma pesquisa nos cinco principais pólos do interior de São Paulo, Fernandes e Leite (2002) constataram que das fundições de mercado pesquisadas, $80 \%$ apresentaram 
interesse em sistemas informatizados para gestão da produção e que o maior empecilho para a automação/informatização, assinalada por 76,7\% das empresas, é a disponibilidade de recursos financeiros. Várias delas possuem alguns sistemas informatizados como, por exemplo, para emissão de ordens de compra, mas apenas uma possui sistema informatizado para a programação da produção.

O objetivo deste trabalho consiste em estudar o modelo e o algoritmo proposto em (ARAUJO, 2003) para uma fundição de mercado de pequeno porte localizada no interior de São Paulo. O método atual de resolução depende de um software comercial, dificultando assim sua implantação em fundições de pequeno porte. Logo, é proposta uma heurística independente de quaisquer softwares comerciais, baseada na decomposição do problema em dois subproblemas menores. No primeiro subproblema são determinadas quais ligas e em que quantidade deverão ser fundidas em cada período do horizonte de planejamento e o segundo, a partir das ligas calculadas, determina quais itens deverão ser feitos em cada um destes períodos. Para a resolução destes subproblemas, recorre-se à uma heurística lagrangiana baseada em transferências de lotes de ligas e de itens.

Para validar esta abordagem, foram feitas comparações com uma simulação de 5 dias de produção na fundição estudada e com o melhor resultado obtido até o momento (ARAUJO et al., 2006a).

Embora o trabalho estudado tenha sido desenvolvido para um caso particular, o mesmo pode ser estendido para várias outras fundições de mercado de pequeno e médio porte que necessitam de melhoria na estrutura organizacional, mas que, no entanto, não dispõem de muitos recursos para investimento em pesquisas.

Este trabalho é composto por seis capítulos. No Capítulo 1 é apresentada uma revisão bibliográfica dos trabalhos desta área. No Capítulo 2 é descrito o problema abordado. A abordagem de resolução proposta e a heurística desenvolvida são descritas respectivamente, nos Capítulos 3 e 4 . No Capítulo 5 é apresentado um estudo de caso e por fim, no Capítulo 6, são discutidas as conclusões e propostas futuras. 


\section{Revisão bibliográfica}

\subsection{Considerações iniciais}

O dimensionamento de lotes é um problema de planejamento que envolve a determinação de quanto produzir em cada um dos períodos de um horizonte de planejamento. O objetivo é encontrar um plano de produção de custo mínimo, capaz de atender a demanda dos produtos sem violar a capacidade de produção disponível.

Em (KARIMI et al., 2003), são destacadas características que influenciam a classificação, modelagem e complexidade das decisões do problema de dimensionamento de lotes. As características destacadas pelos autores são:

- horizonte de planejamento: é o intervalo de tempo para o qual a produção vai ser planejada, que pode ser finito ou infinito; contínuo ou discreto. Em relação aos períodos de tempo pode ser big bucket, quando o período é longo o suficiente para produzir múltiplos itens, ou small bucket, quando o período é tão curto, que apenas um item pode ser produzido em cada período de tempo. Além disso, também podemos considerar o horizonte de planejamento rolante, quando existe incerteza quanto aos dados; 
- número de estágios: o problema de dimensionamento de lotes pode ter um único estágio (monoestágio) ou múltiplos estágios de planejamento (multiestágio). Um sistema tem um único estágio quando a demanda pelos itens é independente de outros itens e tem múltiplos estágios quando a demanda de um item depende da produção de outros itens. Os problemas com múltiplos estágios de produção, em geral, são mais difíceis de resolver que aqueles com um único estágio;

- número de itens: um único item ou múltiplos itens. Neste último, todos os itens a serem produzidos utilizam os mesmos recursos, e, portanto, o problema se torna mais complexo. Bitran e Yanasse (1982) mostraram que vários casos com um único item, que podem ser resolvidos em tempo polinomial, se tornam NP-hard quando um segundo item é introduzido;

- restrições de capacidade: os recursos disponíveis para a produção podem ser ilimitados (não-capacitado) ou limitados (capacitado). Quando os recursos são limitados o problema de planejamento da produção se torna significativamente mais complexo;

- tipo de demanda: pode ser determinística ou probabilística, ou ainda, estática ou dinâmica;

- estoque: no problema de dimensionamento de lotes, pode ser permitido o atendimento da demanda com ou sem atraso, ou ainda, pode haver custo associado à perda da demanda, caso não seja possível atender a demanda sem atraso. Em alguns casos, são considerados simultaneamente, os custos para o atraso no atendimento da demanda e também os custos para a perda da demanda;

- itens perecíveis: os itens a serem produzidos podem ser perecíveis, o que pode limitar o tempo de seu armazenamento. Em casos extremos, os itens não podem ser armazenados;

- preparação para produção: outra característica de fundamental importância para a solução do problema de dimensionamento de lotes é a existência ou não de custos e tempos associados à preparação para a produção de um determinado item. Florian et al. (1980) provaram que vários problemas com um único item e custos 
de preparação são NP-hard e segundo Maes et al. (1991), o problema de encontrar uma solução factível quando o tempo de preparação é considerado, é NP-completo.

A seguir é apresentada uma revisão bibliográfica sobre o problema de dimensionamento de lotes, onde são enfatizados os trabalhos que abordam o problema com um único estágio (uma revisão mais completa também pode ser encontrada em (BAHL et al., 1987)). E em seguida, são apresentados trabalhos direcionados ao setor de fundições.

\subsection{O problema de dimensionamento de lotes mono- estágio}

A motivação para estudar os problemas de dimensionamento de lotes monoestágio está no fato de que, além de sua potencialidade para aplicações práticas, o mesmo aparece como um subproblema em diversos casos, desta forma, implementações eficientes dos bons algoritmos disponíveis, melhoram o desempenho de algoritmos projetados para problemas mais gerais.

Este trabalho aborda o problema de dimensionamento de lotes em um único estágio, com múltiplos itens, capacitado, com custos de preparação, possibilidade de atraso no atendimento da demanda (backlogging) e envolve um horizonte de planejamento finito com demanda determinística e dinâmica. A abordagem utilizada na resolução é a relaxação lagrangiana, gerando problemas com um único item e não capacitado. Desta forma, é feita a revisão dos problemas com um único item sem restrições de capacidade e dos problemas com múltiplos itens com restrições de capacidade, principalmente, os trabalhos que envolvem relaxação lagrangiana.

\subsubsection{Problemas com um único item sem restrições de capaci- dade}

Em (WOLSEY, 1995) a atenção é voltada para o problema do dimensionamento de lotes não-capacitado (PDL) com um item. Para os problemas que envolvem uma máquina, um estágio, múltiplos itens e restrições de capacidade, geralmente, três algoritmos para resolução são utilizados: relaxação lagrangiana, geração de colunas ou planos de corte. Estes algoritmos lidam com subproblemas envolvendo o PDL que podem ser resolvidos 
otimamente, em tempo $\mathrm{O}\left(n^{2}\right)$, pelo algoritmo de programação dinâmica desenvolvido por Wagner e Within (1958). Evans (1985) propôs uma implementação eficiente do algoritmo que não reduz sua complexidade, mas se mostrou mais eficiente na prática. Federgruen e Tzur (1991), Wagelmans et al. (1992), e Aggarwal e Park (1993) apresentam implementações mais eficientes para resolver o problema com complexidade $\mathrm{O}(n \log n)$.

Zangwill (1969) abordou o caso em que a demanda pode ser atendida com atraso (backlogging). O autor foi o primeiro a ressaltar a importância do uso de redes na representação de alguns problemas de planejamento da produção. O modelo analisado tem por objetivo encontrar um plano de produção que minimize os custos de produção, de preparação e de estoque. O problema foi representado como um problema de fluxo de custo mínimo numa redes com custo côncavo nos arcos e uma única fonte, facilitando o desenvolvimento de algoritmos de programação dinâmica eficientes para o cálculo de planos de produção ótimos. Pochet e Wolsey (1988) propuseram a reformulação do problema e sua solução através de planos de corte. Federgruen e Tzur (1993) e Aggarwal e Park (1993) propuseram algoritmos com complexidade $\mathrm{O}(n \log n)$ para a solução do problema que tinha complexidade $\mathrm{O}\left(n^{2}\right)$.

Casarotti (2005) propõe três heurísticas para o problema com backlogging que foram baseadas na proposta apresentada por Axsäter (1980) para o problema sem backlogging, o qual foi modelado como um problema de roteamento de veículos. Testes realizados para a comparação com o algoritmo ótimo apresentado em (ZANGWILL, 1969) apresentaram soluções de boa qualidade com baixo tempo computacional.

Toledo e Shiguemoto (2005) estudaram o caso do problema de dimensionamento de lotes envolvendo vários centros produtivos sem restrições de capacidade e com a demanda podendo ser atendida com e sem atraso. Foi proposta uma implementação eficiente do algoritmo de Zangwill (1969) para um centro produtivo e então foi feita a extensão para vários centros produtivos paralelos. Os resultados computacionais mostram o bom desempenho das implementações eficientes.

Outros métodos e algoritmos para o problema monoestágio não-capacitado podem ser encontrados em (KARIMI et al., 2003) e em (BRAHIMI et al., 2006). Neste último também são apresentadas versões diferentes para a formulação do problema e algumas extensões, além da análise da complexidade para o problema capacitado. 


\subsubsection{Problemas com múltiplos itens com restrições de capaci- dade}

Como apresentado em (KARIMI et al., 2003), os métodos de solução para o problema podem ser classificadas em três categorias principais: métodos exatos, heurísticas especializadas e heurísticas baseadas em programação matemática. As heurísticas de relaxação se enquadram na terceira categoria. Para os problemas sem backlogging esta revisão é restringida a problemas que utilizam a relaxação lagrangiana.

Devido a complexidade do problema, o trabalho apresentado em (DIABY et al., 1992a) é um dos poucos métodos ótimos que foram propostos para o problema de dimensionamento de lotes capacitado. O problema considera o tempo de preparação e os autores desenvolveram um método branch-and-bound no qual os limitantes são gerados por relaxação lagrangiana e os custos duais atualizados pelo método do subgradiente.

No entanto, várias heurísticas foram propostas. Dentre elas a apresentada por Trigeiro et al. (1989), que aplicaram relaxação lagrangiana ao problema, decompondo-o em um conjunto de subproblemas sem restrições de capacidade com um único item, que podem ser resolvidos pelo algoritmo de Wagner e Within (1958). Os multiplicadores lagrangianos são atualizados pelo método do subgradiente e a cada passo um procedimento é aplicado para tentar construir uma solução factível.

Pode-se destacar também Lozano et al. (1991), onde os autores propuseram a relaxação lagrangiana do problema pelo método primal-dual, obtendo um algoritmo similar ao proposto por Trigeiro et al. (1989). As principais diferenças estão no procedimento de factibilização e no método de otimização que garante um acréscimo da função dual a cada iteração resultando na convergência finita deste.

Em (DIABY et al., 1992b), é proposta uma heurística onde é utilizado um procedimento baseado em relaxação lagrangiana das restrições de capacidade para tomar as decisões de quando cada item deve ser produzido. Fixados os períodos onde existe produção, é resolvido um problema de transporte para determinar as quantidades a serem produzidas.

Araujo e Arenales (2000) propuseram uma modificação na fase de factibilização da heurística desenvolvida por Trigeiro et al. (1989). A escolha dos períodos e itens a serem transferidos levam em consideração as condições de folgas complementares (GEOFFRION, 
1974). Testes realizados apresentaram bons resultados.

Uma revisão mais detalhada de heurísticas para o problema pode ser encontrada em (MAES; WASSENHOVE, 1988). Em (DREXL; KIMMS, 1997) é feita uma revisão de modelos que envolvem dois problemas integrados: o dimensionamento e o sequenciamento de lotes, ou seja, dado um planejamento pré-estabelecido, sequenciar tarefas em uma ou várias máquinas, de forma a otimizar uma função objetivo.

Poucos trabalhos que abordam o backlogging foram encontrados na litetura. Dentre eles temos o apresentado por Millar e Yang (1994). Os autores apresentam dois algoritmos para resolver a formulação baseada em redes do problema de dimensionamento de lotes. Um é baseado na relaxação lagrangiana e outro na decomposição lagrangiana. Na abordagem de relaxação, são relaxadas as restrições que forçam o setup quando há produção e então são colocadas na função objetivo com multiplicadores lagrangianos resultando em dois subproblemas: um problema de transporte e um problema de programação inteira. A abordagem de decomposição explora o problema de transporte e $N$ PDLs com um único item e backlogging. Ambas abordagens utilizam o método do subgradiente na resolução do problema e se mostraram mais rápidas que a abordagem proposta por Pochet e Wolsey (1988) para o problema reformulado como um problema de caminho mínimo.

Karimi e Fatemi Ghomi (2001) abordam o problema de dimensionamento de lotes capacitado multi-item com backlogging e setup carry-over. O problema é formulado como um modelo de programação inteira mista para o qual é apresentada uma heurística composta de quatro elementos: regra de transferência de demanda, regra de determinação dos lotes, condições de factibilidade e determinação do setup carry-over. Testes mostram que o algoritmo heurístico é rápido e apresenta soluções de boa qualidade.

Karimi, Fatemi Ghomi e Wilson (2006) utilizam a heurística apresentada em (KARIMI; GHOMI, 2001) para obter uma solução factível inicial. Então a solução é melhorada resolvendo-se um problema de fluxo de rede de custo mínimo, redefinido a partir do modelo de programação inteira mista original. A solução obtida é usada como uma solução inicial para a heurística de busca tabu, com o valor dos movimentos explorados utilizando o mesmo problema de fluxo de rede. Foram obtidas soluções de boa qualidade. 


\subsection{Trabalhos específicos no setor de fundições}

Poucos trabalhos foram encontrados envolvendo problemas de planejamento e programação da produção orientados para o setor de fundições, principalmente, fundições de pequeno e médio porte.

O trabalho sobre fundições de pequeno porte apresentado em (ARAUJO et al., 2004) aborda um problema de programação inteira mista, com restrição de capacidade, custo de preparação e considera a possibilidade de atraso no atendimento da demanda. O objetivo principal é minimizar atrasos. Devido a complexidade do problema, os autores propõem duas heurísticas baseadas em um método de horizonte rolante. A primeira utiliza o método relaxe-e-fixe, que numa primeira fase mantém as variáveis binárias referentes ao primeiro dia de programação e relaxa as demais. Após fixadas as variáveis binárias, retoma a condição de integralidade das variáveis relaxadas e então é obtida uma solução factível inteira. A segunda utiliza um algoritmo de busca local na primeira fase do método relaxe-e-fixe na tentativa de obter melhores soluções na fixação das variáveis binárias. O segundo método apresenta resultados computacionais melhores.

Em (ARAUJO et al., 2006b) é apresentado um modelo para fundições de mercado de pequeno porte que considera tempo de preparação. Foram analisadas outras duas técnicas para tentar melhorar o resultado obtido pelo método de busca local apresentado em (ARAUJO et al., 2004): a técnica de redução de vizinhança e a meta-heurística simulated anneling. A utilização da meta-heurística simulated anneling apresentou resultados melhores.

O trabalho apresentado em (ARAUJO et al., 2006a) considera custo e tempo de preparação dependentes da sequência. Foram desenvolvidos um modelo baseado na técnica de horizonte rolante e um procedimento relaxe-e-fixe $(\mathrm{RF})$. No primeiro passo do método relaxe-e-fixe foram desenvolvidas três variantes de busca local: heurística decrescente $(\mathrm{DH})$, redução de vizinhança $(\mathrm{DN})$ e simulated anneling $(\mathrm{SA})$ que foram comparados com a programação manual de uma fundição de pequeno porte.

Silva e Morabito (2004) propõem uma abordagem para otimizar a programação de cargas de forno em fundições de mercado de pequeno porte baseada nos problemas de corte e empacotamento (PCE) unidimensionais (MORABITO; ARENALES, 1992). Nesta abordagem, as peças a serem fundidas correspondem às "unidades pequenas" (com dimensões 
iguais aos pesos das peças), os fornos correspondem às "unidades grandes" (com dimensões iguais às capacidades dos fornos), e o problema envolve cortar (ou empacotar) unidades pequenas a partir (dentro) de unidades grandes, de maneira a otimizar o aproveitamento destas e satisfazer prazos de entrega e restrições de processo. Foi realizado um estudo de caso em uma fundição que possui três fornos e os resultados verificados em duas semanas de operação foram melhores que os obtidos pela fábrica, pois toda carteira de pedidos foi produzida com um dia a menos de produção (redução de 20\%).

Em (SANTOS-MEZA et al., 2002) é feito o estudo de uma fundição de médio porte, que tem apenas um forno, várias máquinas de moldagem e que deve atender uma demanda conhecida de diferentes tipos de itens, fabricados a partir de diferentes ligas. Devem ser decididas quais ligas deverão ser produzidas no forno em cada período e então o número de itens produzidos em cada máquina de moldagem. Considerando o forno como gargalo da produção, foram desenvolvidos dois algoritmos. O primeiro deles considera que apenas uma liga pode produzir todos os itens, resultando em um modelo de programação linear, o qual é resolvido otimamente. Considerando ligas diferentes, o modelo se torna de programação inteira mista e é utilizado um algoritmo heurístico baseado em uma relaxação do problema. A cada período de planejamento, o modelo é relaxado para o problema com apenas uma liga (resolvido otimamente), e então uma heurística que fixa as ligas em cada período é utilizada. Os resultados mostram a eficiência dos métodos heurísticos específicos na resolução de problemas de programação inteira grandes.

Em (ARAUJO; ARENALES, 2003) são realizadas extensões do proposto em (SANTOSMEZA et al., 2002), considerando custos de preparação e atraso na entrega dos pedidos. Esta nova abordagem fornece ao decisor possíveis rearranjos na demanda, caso não seja possível o atendimento sem atraso.

Duda e Osyczka (2005) utilizam uma abordagem para a modelagem do problema similar ao apresentado em (SANTOS-MEZA et al., 2002), no entanto, consideram uma função multicritério que maximiza a utilização dos fornos e máquinas de moldagem e minimiza o atraso na produção. A resolução do modelo é dada por algoritmos evolutivos multiobjetivo. Em (DUDA, 2005) é apresentado um estudo do uso de algoritmos genéticos aplicados ao problema de dimensionamento de lotes em fundições. São testadas três variações de algoritmos genéticos e respectivas funções de reparo, e então, os resultados são comparados com os obtidos por um software comercial. 
Em (LANDMANN, 2005) foi desenvolvido um modelo heurístico para a programação simultânea e integrada da fusão e da moldagem, inserido no sistema de PCP, em fundições mecanizadas de metais ferrosos. A construção do modelo foi baseada nos conceitos da lógica fuzzy, que oferecem mecanismos para a representação e manipulação do conhecimento de especialistas. Foram coletadas informações de quatro fundições de mercado e foi feita uma comparação do modelo heurístico com um caso prático e este mostrou um desempenho equivalente em alguns dias, e superior em outros.

Em relação à fundições de grande porte, é apresentado um estudo de caso de uma fundição cativa em (ARAUJO; ARENALES, 2004). Na fundição existem três linhas de moldagem e dois conjuntos de fornos em operação que produzem apenas dois tipos principais de liga. Deve ser decidido qual liga deve ser produzida no forno em cada período e a quantidade de cada item a ser produzida em cada máquina de moldagem, logo, foi proposto um modelo matemático de otimização inteira mista. Foram realizados testes com um pacote comercial e comparações com o resultado obtido na prática mostram expressivos ganhos de produtividade e redução de atrasos na entrega dos pedidos.

É possível encontrar uma revisão de trabalhos de planejamento e programação da produção aplicados à indústria de fabricação de aço em (TANG et al., 2001), o qual é voltada para grandes siderúrgicas. Outros trabalhos sobre fundições de grande porte são apresentados em (ARAUJO, 2003). 


\section{CAPÍTULO}

2

\section{Descrição do problema abordado}

\subsection{Considerações iniciais}

A motivação deste trabalho foi o estudo apresentado por Araujo (2003) em sua tese de doutorado sobre modelos e métodos para o planejamento da produção aplicados a uma fundição de pequeno porte situada na cidade de São Carlos e que representa uma classe significativa de fundições no país. Este setor caracteriza-se como uma importante indústria primária que fornece bens intermediários para diversas outras, tais como: automotivas, siderúrgicas e construção.

Neste capítulo, é apresentada a descrição do problema, bem como a modelagem matemática desenvolvida por Araujo (2003).

\subsection{Descrição do problema}

Conforme apresentado em (ARAUJO, 2003), um fluxograma do processo produtivo da fundição de mercado, objeto de estudo deste trabalho, pode ser ilustrado como mostra a Figura 2.1.

Os itens demandados estão em uma carteira de pedidos que contém todas as suas 


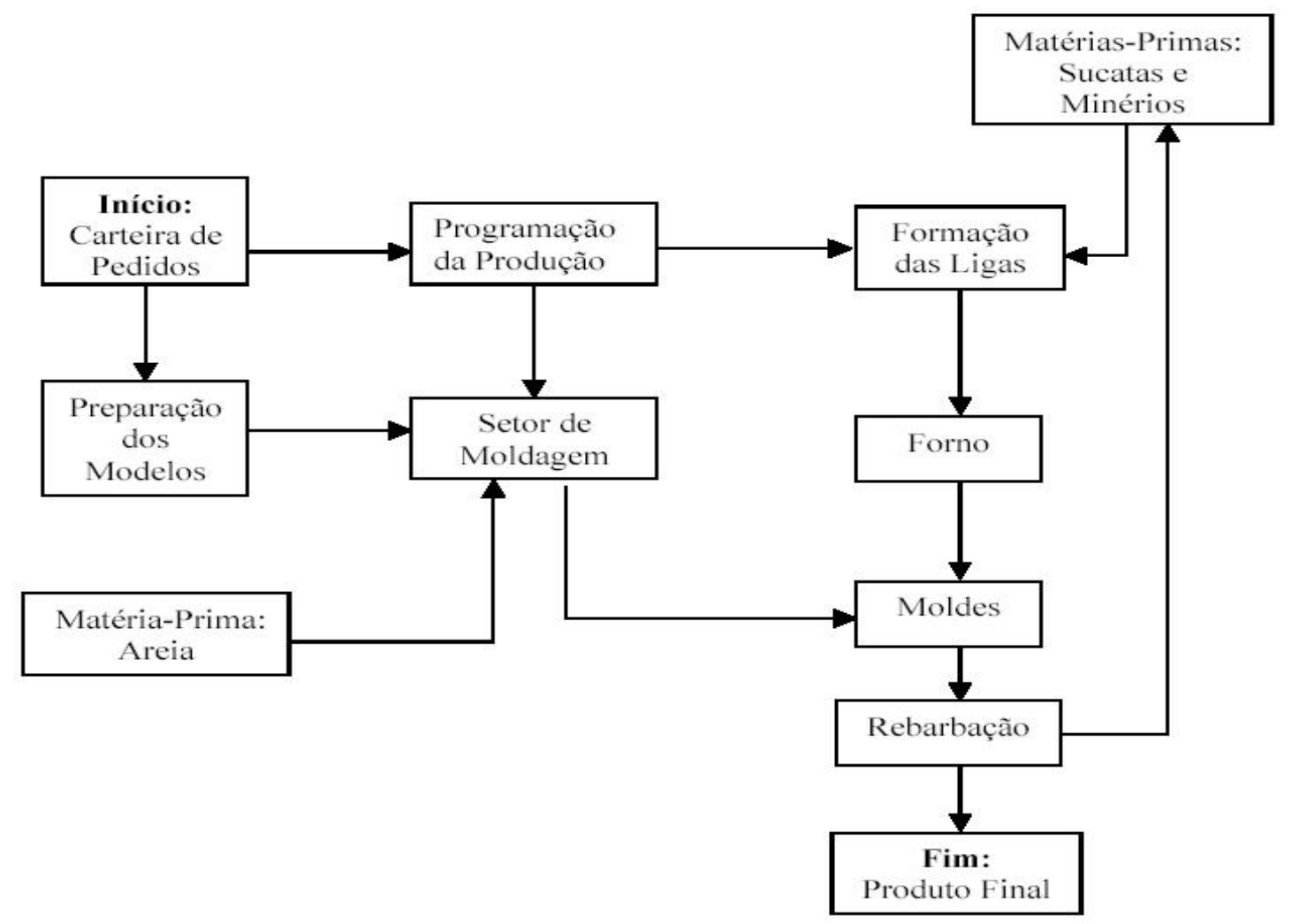

Figura 2.1: Processo de produção na fundição (ARAUJO, 2003).

especificações. Esta é passada para os setores de Programação da Produção e de Preparação dos Modelos. No Setor de Programação da Produção, o gerente de processos toma a decisão de quais itens produzir de acordo com sua experiência, de forma que itens mais atrasados e pedidos de clientes especiais tenham maior prioridade e de modo que a capacidade total do forno seja aproveitada ao máximo. Em função disso, também são definidas as ligas a serem fundidas.

A tomada de decisão do Setor de Programação da Produção é passada para o Setor de Moldagem e para a formação das ligas. O Setor de Moldagem utiliza os modelos vindos do Setor de Preparação de Modelos e a areia (como matéria-prima) para fabricar os moldes. Na formação das ligas é feita a mistura das matérias-primas (sucatas e minérios de ferro). Em geral, há muitas formas de combinar essas diferentes matérias-primas para atingir a composição desejada de determinada liga. A utilização do clássico problema da mistura (JOHNSON; MONTGOMERY, 1974) gera carregamentos de forno que minimizam os custos de matéria-prima, a partir das composições das sucatas existentes e outros materiais, e uma aplicação foi desenvolvida para a fundição (CONSTANTINO, 2000). Esta mistura é então colocada no forno para a fusão. A indústria conta com dois fornos, o primeiro 
com capacidade de $120 \mathrm{Kg}$ (tempo de fusão de $45 \mathrm{~min}$ ) e o segundo com capacidade de $360 \mathrm{Kg}$ (tempo de fusão de $1 \mathrm{~h}$ 55min), sendo possível a utilização de apenas um forno por vez devido ao contrato de energia elétrica da fundição. Além disso, devido ao alto tempo de preparação, não é aconselhável que haja troca de fornos durante um mesmo dia de trabalho. Assim, é preferível subutilizar o forno de $360 \mathrm{Kg}$ (desde que seja utilizado pelo menos $120 \mathrm{Kg}$ ) a desligar o forno e ligar o de $120 \mathrm{Kg}$.

Após a fusão, a liga é vazada nos moldes já preparados e a sobra é despejada no chão para a formação de lingotes, que retornarão para o estoque de matérias-primas. O tempo de solidificação para a maioria das ligas é 10 min. Após o vazamento, a peça é colocada na água de modo que haja o choque térmico e, então, é feita a rebarbação. A rebarba retirada da peça volta a ser matéria-prima (sucata) e, finalmente, os itens são disponibilizados para entrega.

\subsection{Modelagem matemática}

Na modelagem matemática, Araujo (2003) fez algumas simplificações de forma a viabilizar a resolução do problema, tal como considerar apenas o forno maior (360 Kg) no planejamento. Ficou decidido, juntamente com o proprietário da indústria, que caso a soma das demandas de todos os itens de uma determinada liga seja menor que $120 \mathrm{Kg}$, tais demandas seriam transferidas da carteira de pedidos para uma carteira separada até completar uma quantidade de cargas suficientes para serem feitas em um dia de trabalho somente com o forno de $120 \mathrm{~kg}$. Caso existam itens com as demandas vencendo antes que isto aconteça, existe a possibilidade de fazer hora extra, no sábado, com o forno menor.

Para a fundição em questão o gargalo de produção são os fornos, logo é abordado o problema de planejamento de produção de múltiplos itens em um único estágio de produção. O objetivo é encontrar o plano de produção que minimize os custos de atraso, de estoque e de preparação. O horizonte de planejamento é finito e subdividido em períodos menores. A capacidade de produção nos períodos é limitada e a demanda pelos itens é previamente determinada. O plano de produção deve respeitar a capacidade de produção e o atendimento da demanda dos itens. Em cada um dos períodos deve ser determinada a liga metálica a ser fundida, logo apenas os itens feitos a partir da liga fundida podem ser produzidos. 
Este problema pertence à área de otimização combinatória e pode ser modelado como é proposto em (ARAUJO, 2003). Os parâmetros e as variáveis do modelo são definidos a seguir:

\section{Índices:}

- $k=1, \ldots, K$ tipos de ligas;

- $i=1, \ldots, N$ tipos de itens;

- $t=1, \ldots, T$ períodos de tempo (cargas do forno).

\section{Dados do problema:}

- Cap: capacidade do forno por período;

- $\rho_{i}$ : peso bruto do item $i$;

- $d_{i, t}$ : demanda do item $i$ no período $t$;

- $S(k)$ : conjunto de itens $i$ que usam a liga $k$ (cada item utiliza um, e somente um, tipo de liga, ou seja: $\{1, \ldots, N\}=S(1) \cup \cdots \cup S(K), S(h) \cap S(j)=\varnothing, \forall h \neq j)$;

- $H_{i, t}^{-}$: penalidade pelo atraso na entrega de uma unidade do item $i$ no período $t$;

- $H_{i, t}^{+}$: penalidade por antecipação de uma unidade do item $i$ no período $t$;

- $s_{k}$ : penalidade pela preparação da liga $k$.

\section{Variáveis do problema:}

- $X_{i, t}$ : quantidade produzida do item $i$ no período $t$;

- $I_{i, t}^{+}$: quantidade estocada do item $i$ no final do período $t$;

- $I_{i, t}^{-}$: quantidade atrasada do item $i$ no final do período $t$;

- $Y_{t}^{k}$ : variável binária $\left(Y_{t}^{k}=1\right.$ indica que o forno é preparado para produzir a liga $k$ no período $t$, caso contrário, $\left.Y_{t}^{k}=0\right)$; 
- $Z_{t}^{k}$ : variável que indica se é cobrado a penalidade pela preparação da liga $k$ no período $t$ : $Z_{t}^{k}=0$ se $Y_{t-1}^{k} \geq Y_{t}^{k}$ e $Z_{t}^{k}=1$, caso contrário. Embora esta variável seja binária em essência, pode ser modelada como contínua.

\section{Modelo Matemático Completo:}

\section{Minimizar}

$$
\sum_{i=1}^{N} \sum_{t=1}^{T}\left(H_{i, t}^{-} I_{i, t}^{-}+H_{i, t}^{+} I_{i, t}^{+}\right)+\sum_{k=1}^{K} \sum_{t=1}^{T}\left(s_{k} Z_{t}^{k}\right)
$$

\section{Sujeito a}

$$
\begin{array}{ll}
I_{i, t-1}^{+}-I_{i, t-1}^{-}+X_{i, t}-I_{i, t}^{+}+I_{i, t}^{-}=d_{i, t} & i=1, \ldots, N ; t=1, \ldots, T ; \\
\sum_{i \in S(k)} \rho_{i} X_{i, t} \leq \operatorname{Cap} Y_{t}^{k} & k=1, \ldots, K ; t=1, \ldots, T ; \\
Z_{t}^{k} \geq Y_{t}^{k}-Y_{t-1}^{k} & k=1, \ldots, K ; t=1, \ldots, T ; \\
\sum_{k=1}^{K} Y_{t}^{k} \leq 1 & t=1, \ldots, T ; \\
Y_{t}^{k} \in\{0,1\}, Y_{0}^{k}=0 & k=1, \ldots, K ; t=1, \ldots, T ; \\
Z_{t}^{k} \geq 0 & k=1, \ldots, K ; t=1, \ldots, T ; \\
X_{i, t} \geq 0, \text { inteira } & i=1, \ldots, N ; t=1, \ldots, T ; \\
I_{i, t}^{+} \text {e } I_{i, t}^{-} \geq 0, I_{i, 0}^{+}=I_{i, 0}^{-}=0 & i=1, \ldots, N ; t=1, \ldots, T .
\end{array}
$$

A função objetivo (2.1) busca retratar o objetivo da empresa, que consiste em minimizar os atrasos na entrega dos pedidos. Para tanto, uma penalidade é associada às variáveis que representam o atraso no atendimento da demanda. Além disso, também são consideradas penalidades para antecipação da produção e para preparação das ligas. As restrições (2.2) representam as equações de balanço de estoque e consideram tanto estoques negativos (atraso) como positivos (antecipação). A limitação da capacidade do forno é expressa em (2.3), onde a soma da produção de todos os itens é limitada a capacidade do forno. Estas restrições também asseguram que os itens que utilizam determinada liga só podem ser produzidos quando essa liga for preparada. Mudanças de ligas são representadas pelas restrições (2.4). As restrições (2.5) garantem que apenas uma liga pode ser produzida em cada período. As restrições (2.6) - (2.9) garantem a não-negatividade das variáveis e a integralidade das variáveis $Y_{t}^{k}$ e $X_{i, t}$.

Segundo (ARAUJO, 2003), devido às características da indústria, onde existem alguns 
pedidos para a fabricação de apenas 1 ou 2 itens pesados, as variáveis de produção $X_{i t}$ são inteiras e não podem ser relaxadas como na maioria dos modelos de dimensionamento de lotes. Além disso, como os itens têm de ser fabricados a partir de fornadas individuais não é possível deixar um molde com apenas parte de liga e na próxima fornada completar o molde.

Conforme apresentado em (ARAUJO, 2003) $\alpha_{i, t}$ representa os dias de atraso do item $i$ no período $t$ (para pedidos que não estão em atraso, $\alpha_{i, t}$ recebe valores não positivos, dependendo da quantidade de dias entre o início da programação e o dia de entrega do pedido e $\alpha_{i, t}=0$ significa que o prazo de entrega do item vence no período $t$ ). Neste caso, algumas considerações sobre os dados do problema devem ser feitas:

- definindo $L$ como o número de fornadas em cada dia de programação, as demandas $d_{i, t}$ são positivas somente nos períodos múltiplos de $L$, ou seja, ao final de cada dia de programação;

- as penalidades pelo atraso e antecipação, $H_{i, t}^{-}$e $H_{i, t}^{+}$, respectivamente, também são positivos somente nos períodos múltiplos de $L$. São calculados da seguinte forma (ARAUJO et al., 2004):

$$
\begin{aligned}
& \text { Para } \mathrm{t} \neq L, 2 L, 3 L, \ldots \\
& \quad H_{i, t}^{-}=H_{i, t}^{+}=0 ; \\
& \text { Para } t=L, 2 L, 3 L, \ldots \text { e considerando } G \text { um número grande, } \\
& \quad \text { Se } \alpha_{i, t} \geq 0 \text { então } H_{i, t}^{-}=\rho_{i}\left(\alpha_{i, t}+1\right) ; H_{i, t}^{+}=G ; \\
& \quad \text { Senão } H_{i, t}^{+}=\rho_{i} / 10 ; H_{i, t}^{-}=G ;
\end{aligned}
$$

Como as penalidades por atraso são subjetivamente estimadas e a carteira de pedidos é atualizada com freqüência dentro do horizonte de planejamento, na prática a solução ótima requer ajustes periódicos, logo, foram propostas em (ARAUJO, 2003) e (ARAUJO et al., 2004) heurísticas baseadas na técnica de horizonte rolante. 


\section{CAPÍTULO \\ 3}

\section{Abordagem proposta para resolução}

\subsection{Considerações iniciais}

Neste capítulo é proposta uma nova abordagem para a resolução do problema estudado. Esta abordagem é baseada na decomposição do problema em dois subproblemas: o planejamento da produção das ligas e o planejamento da produção dos itens (peças). Ambos foram resolvidos utilizando o pacote de otimização CPLEX versão 7.5 (ILOG, 2001). Testes computacionais foram realizados para a avaliação da estratégia proposta e são apresentados no final do capítulo.

\subsection{Problema de definição das ligas}

Para a definição do problema das ligas a serem fundidas, considere as restrições (2.2). Multiplicando cada termo por $\rho_{i}$ é obtida a demanda de liga necessária para produzir o item $i$ no período $t$, como mostrado a seguir:

$$
\rho_{i} I_{i, t-1}^{+}-\rho_{i} I_{i, t-1}^{-}+\rho_{i} X_{i, t}-\rho_{i} I_{i, t}^{+}+\rho_{i} I_{i, t}^{-}=\rho_{i} d_{i, t} \quad i=1, \ldots, N ; \quad t=1, \ldots, T
$$

em que: 
$\rho_{i} I_{i, t-1}^{+}$: quantidade (em Kg) do item $i$ estocada no período $t-1$;

$\rho_{i} I_{i, t-1}^{-}$: quantidade (em $\mathrm{Kg}$ ) do item $i$ atrasada no período $t-1$;

$\rho_{i} X_{i, t}$ : quantidade (em $\mathrm{Kg}$ ) do item $i$ produzida no período $t$;

$\rho_{i} I_{i, t}^{+}$: quantidade (em $\mathrm{Kg}$ ) do item $i$ estocada no período $t$;

$\rho_{i} I_{i, t}^{-}$: quantidade (em $\mathrm{Kg}$ ) do item $i$ atrasada no período $t$;

$\rho_{i} d_{i, t}$ : demanda (em $\mathrm{Kg}$ ) do item $i$ no período $t$.

Seja $S(k)$ o conjunto de itens $i$ que utilizam a liga $k, k=1, \ldots, K$, conforme definido no Modelo Completo. Seguindo esta mesma idéia, a demanda no período $t$, para determinada liga $k$ é calculada como a soma de todas as restrições referentes aos itens pertencentes ao conjunto $S(k)$ :

$$
\begin{gathered}
\sum_{i \in S(k)} \rho_{i} I_{i, t-1}^{+}-\sum_{i \in S(k)} \rho_{i} I_{i, t-1}^{-}+\sum_{i \in S(k)} \rho_{i} X_{i, t}-\sum_{i \in S(k)} \rho_{i} I_{i, t}^{+}+\sum_{i \in S(k)} \rho_{i} I_{i, t}^{-} \\
=\sum_{i \in S(k)} \rho_{i} d_{i, t} \quad k=1, \ldots, K ; \quad t=1, \ldots, T .
\end{gathered}
$$

em que:

$\sum_{i \in S(k)} \rho_{i} I_{i, t-1}^{+}:$quantidade (em kg) da liga $k$ estocada no período $t-1$;

$\sum_{i \in S(k)} \rho_{i} I_{i, t-1}^{-}:$quantidade (em kg) da liga $k$ atrasada no período $t-1$;

$\sum_{i \in S(k)} \rho_{i} X_{i, t}$ : quantidade (em $\mathrm{kg}$ ) da liga $k$ produzida no período $t$;

$\sum_{i \in S(k)} \rho_{i} I_{i, t}^{+}$: quantidade $(\mathrm{em} \mathrm{kg})$ da liga $k$ estocada no período $t$

$\sum_{i \in S(k)} \rho_{i} I_{i, t}^{-}$: quantidade (em kg) da liga $k$ atrasada no período $t$;

$\sum_{i \in S(k)} \rho_{i} d_{i, t}$ : demanda (em kg) da liga $k$ no período $t$.

Redefinindo-se as variáveis, obtém-se:

$$
E_{k, t-1}^{+}-E_{k, t-1}^{-}+\sum_{i \in S(k)} \rho_{i} X_{i, t}-E_{k, t}^{+}+E_{k, t}^{-}=D_{k, t} \quad k=1, \ldots, K ; \quad t=1, \ldots, T
$$

Como a demanda pelas ligas é positiva, apenas ao final de cada dia de programação, é possível redefinir o período $t$ (cargas de forno) como $t l$ (dias de programação). Tomando $A_{k, t l}$ como o número de vezes que a liga $k$ é fundida no período $t l$ e sabendo que de acordo com as restrições (2.3), uma vez que uma liga é escolhida para fusão, ela ocupa, no máximo, a capacidade máxima do forno, tem-se que $A_{k, t l}$ pode ser multiplicado por Cap, desta forma pode-se reescrever (3.1) como: 


$$
E_{k, t l-1}^{+}-E_{k, t l-1}^{-}+C a p A_{k, t l}-E_{k, t l}^{+}+E_{k, t l}^{-}=D_{k, t l} \quad k=1, \ldots, K ; \quad t l=1, \ldots, T l .
$$

É necessário garantir também que o número de vezes que as ligas serão fundidas, respeita o limite de $L$ cargas do forno em cada dia de planejamento:

$$
\sum_{k=1}^{K} A_{k, t l} \leq L \quad t l=1, \ldots, T l
$$

Além disso, é necessário que haja produção da liga se houve preparação para a mesma, ou seja:

$$
A_{k, t l} \leq L Y_{k, t l} \quad k=1, \ldots, K ; \quad t l=1, \ldots, T l
$$

Os índices, parâmetros e variáveis do problema das ligas são definidos como:

\section{Índices:}

- $k=1, \ldots, K$ tipos de ligas;

- $t l=1, \ldots, T l$ períodos de tempo (dias de programação).

\section{Dados do problema:}

- Cap: capacidade do forno;

- $L$ : número de fornadas por período;

- $D_{k, t l}$ : demanda da liga $k$ no período $t l$;

- $H_{k, t l}^{-}$: penalidade pelo atraso na entrega de $1 \mathrm{Kg}$ da liga $k$ no período $t l$;

- $H_{k, t l}^{+}$: penalidade por antecipação de $1 \mathrm{Kg}$ da liga $k$ no período $t l$;

- $s_{k}$ : penalidade pela preparação da liga $k$.

\section{Variáveis do problema:}

- $A_{k, t l}$ : número de vezes que a liga $k$ é fundida no período $t l$; 
- $E_{k, t l}^{-}$: quantidade atrasada da liga $k$ (em Kg) no final do período $t l$;

- $E_{k, t l}^{+}$: quantidade estocada da liga $k$ (em $\mathrm{Kg}$ ) no final do período $t l$;

- $Y_{k, t l}$ : variável binária $\left(Y_{k, t l}=1\right.$ indica que o forno é preparado para produzir a liga $k$ no período $t l$, caso contrário, $\left.Y_{k, t l}=0\right)$.

Desta forma o modelo pode ser reescrito para as ligas como:

\section{Modelo Matemático das Ligas:}

\section{Minimizar}

$\sum_{t l=1}^{T l} \sum_{k=1}^{K}\left(H_{k, t l}^{-} E_{k, t l}^{-}+H_{k, t l}^{+} E_{k, t l}^{+}+s_{k} Y_{k, t l}\right)$

Sujeito a

$$
\begin{array}{ll}
E_{k, t l-1}^{+}-E_{k, t l-1}^{-}+\operatorname{Cap}_{k, t l}-E_{k, t l}^{+}+E_{k, t l}^{-}=D_{k, t l} & k=1, \ldots, K ; t l=1, \ldots, T l ; \\
\sum_{k=1}^{K} A_{k, t l} \leq L & t l=1, \ldots, T l ; \\
A_{k, t l} \leq L Y_{k, t l} & k=1, \ldots, K ; t l=1, \ldots, T l ; \\
Y_{k, t l} \in\{0,1\} & k=1, \ldots, K ; t l=1, \ldots, T l ; \\
A_{k, t l} \geq 0, \text { inteira } & k=1, \ldots, K ; t l=1, \ldots, T l ; \\
E_{k, t l}^{+} \text {e } E_{k, t l}^{-} \geq 0, E_{k, 0}^{+}=E_{k, 0}^{-}=0 & k=1, \ldots, K ; t l=1, \ldots, T l .
\end{array}
$$

A função objetivo (3.2) busca minimizar custos de atraso, de estoque e de preparação. As restrições (3.3) são de balanceamento de estoque. As restrições (3.4) limitam o número de fornadas em um dia de trabalho em $L$. As restrições (3.5) asseguram que uma liga só será fundida caso haja sua preparação. As restrições (3.6) definem $Y_{k, t l}$ como variável binária, as restrições (3.7) representam as condições de não-negatividade da variável inteira $A_{k, t l}$ e por fim, as restrições (3.8) representam as condições de não-negatividade das variáveis $E_{k, t l}^{-}$e $E_{k, t l}^{+}$.

Os valores de $H_{k, t l}^{-}$e $H_{k, t l}^{+}$devem ser calculados em função do atraso ou antecipação na produção das ligas, ou seja, definimos $\alpha_{k, t l}$ como os dias de atraso da liga $k$ no período $t l$. Para pedidos que não estão atrasados no período $t l, \alpha_{k, t l}$ recebe valores não positivos referente ao número de dias que faltam para o pedido vencer, e $\alpha_{k, t l}=0$ indica que a data de entrega da liga $k$ é no período $t l$. Desta forma, baseado no cálculo das penalidades para 
o Modelo Completo, as penalidades pelo atraso $\left(H_{k, t l}^{-}\right)$e as penalidades pela antecipação $\left(H_{k, t l}^{+}\right)$, foram definidas como:

$$
\begin{aligned}
& \text { Para } t l=1, \ldots, T l \text { e considerando } G \text { um número grande, } \\
& \text { Se } \alpha_{k, t l} \geq 0 \text { então } H_{k, t l}^{-}=\alpha_{i, t l}+1 ; H_{k, t l}^{+}=G ; \\
& \text { Senão } H_{k, t l}^{+}=1 / 10 ; H_{k, t l}^{-}=G ;
\end{aligned}
$$

É importante notar que ao representar o problema desta forma, é possível atribuir uma penalidade associada ao estoque de liga $\left(H_{k, t l}^{+}\right)$, que é gerada quando a quantidade demandada da liga $k$ no período $t l$ não é múltiplo da capacidade máxima do forno. Como o estoque de liga não faz sentido para a fundição, esta penalidade também pode ser vista como uma representação pela quantidade de forno que deixou de ser utilizada, ou seja, uma representação pela má utilização do forno. Esta penalidade não é representada no Modelo Completo, e testes para avaliar sua relevância são apresentados na Seção 3.4.

A demanda pelas ligas é obtida pelo agrupamento de itens, $\log 0 \alpha_{k, t l}$ pode ser definido de várias formas distintas. Com o intuito de testar qual a melhor forma para agrupar itens, de modo a obter uma melhor configuração de ligas na resolução do Modelo das Ligas, foi definido um novo número de ligas $\operatorname{Kaux}(\operatorname{Kaux} \geq K)$ de forma que uma determinada liga $k$ é subdividida em ligas consideradas diferentes de acordo com algum critério. Foram considerados 5 critérios:

- Critério 1: considera o agrupamento de itens de determinada liga $k$ com mesma data de vencimento, gerando para cada data de vencimento uma liga diferente $($ Kaux $\geq K)$. O número de dias de atraso no início da programação $\left(\alpha_{k a u x, 1}\right)$ é dado pelo $\alpha_{i, 1}$ dos itens agrupados.

- Critério 2: não há subdivisão $(K a u x=K)$ e o número de dias de atraso no início da programação é o maior dentre todos os dias de atraso dos itens produzidos de cada liga $k$, ou seja, $\max \left\{\alpha_{i, 1}, i \in S(k)\right\}$.

- Critério 3: não há subdivisão $(K a u x=K)$ e o número de dias de atraso no início da programação é a média ponderada do número de dias de atraso no início da programação dos itens pertencentes à liga $k$, e a quantidade (em Kg) demandada dos itens: $\frac{\sum_{i \in S(k)} \alpha_{i, 1} \text { pesodemandado }_{i}}{\sum_{i \in S(k)} \text { pesodemandado }_{i}}$, em que pesodemandado $o_{i}=\sum_{t=1}^{T} d_{i, t} \rho_{i}$.

- Critério 4: considera um agrupamento a cada 15 itens de determinada liga $k$ uma liga diferente $($ Kaux $\geq K$ ), e o número de dias de atraso no início da programação 
é calculado da mesma forma que o critério 3 .

- Critério 5: considera uma liga diferente um agrupamento de itens até ser atingido pelo menos $360 \mathrm{Kg}($ Kaux $\geq K)$, e o número de dias de atraso no início da programação é calculado da mesma forma que o critério 3.

Os testes computacionais para a avaliação do melhor critério são apresentados na Seção 3.4 .

\subsection{Problema de definição dos itens}

A partir das variáveis $A_{k, t l}, k=1, \ldots, K$ e $t l=1, \ldots, T l$, obtidas na resolução do Modelo das Ligas, são definidos os períodos de preparação $W_{k, t}, k=1, \ldots, K$ e $t=1, \ldots, T$. Exemplificando, considere que foi definido, para o Problema das Ligas, um novo número de ligas (Kaux) maior que o número de ligas originais $(K)$, de acordo com algum critério apresentado na seção anterior, ou seja, considere que existam 4 ligas originais $(K=4)$ subdivididas em 9 ligas auxiliares $($ Kaux $=9)$, como apresentado na Tabela 3.1:

Tabela 3.1: Exemplo de índices para o mapeamento das ligas.

\begin{tabular}{|c|c|}
\hline Liga original & Ligas auxiliares correspondentes \\
\hline \hline 1 & $1,2,3$ \\
\hline 2 & $4,5,6$ \\
\hline 3 & 7,8 \\
\hline 4 & 9 \\
\hline
\end{tabular}

Supondo $L=10$ e $T l=1$, ou seja, considerando-se apenas um dia de programação. Após obtido o resultado do Problema das Ligas $\left(A_{k a u x, t l}\right)$, digamos: $A_{1,1}=2, A_{2,1}=1$, $A_{4,1}=3, A_{6,1}=1, A_{7,1}=2$, e $A_{9,1}=1$, é feito o mapeamento para as ligas originais $\left(A_{k, t l}\right): A_{1,1}=3, A_{2,1}=4, A_{3,1}=2$, e $A_{4,1}=1$, e então são calculados os períodos com preparação $\left(W_{k, t}\right)$ progressivamente no tempo, ordenados por liga: $W_{1,1}=1, W_{1,2}=1$, $W_{1,3}=1, W_{2,4}=1, W_{2,5}=1, W_{2,6}=1, W_{2,7}=1, W_{3,8}=1, W_{3,9}=1$ e $W_{4,10}=1$.

Para cada liga $k$ é resolvido um problema de dimensionamento de lotes, agora para definição dos itens a serem produzidos. Os índices, parâmetros, variáveis e o problema de determinação dos itens, são definidos como: 


\section{Índices:}

- $i \in S(k)$ tipos de itens da liga $k$;

- $t=1, \ldots, T$ períodos de tempo (cargas do forno).

\section{Dados do problema:}

- Cap: capacidade do forno por período;

- $\rho_{i}$ : peso bruto do item $i$;

- $d_{i, t}$ : demanda do item $i$ no período $t$;

- $S(k)$ : conjunto de itens $i$ que usam a liga $k$ (cada item utiliza um, e somente um, tipo de liga, ou seja: $\{1, \ldots, N\}=S(1) \cup \cdots \cup S(K), S(h) \cap S(j)=\varnothing, \forall h \neq j)$;

- $H_{i, t}^{-}$: penalidade pelo atraso na entrega de uma unidade do item $i$ no período $t$, calculada da mesma forma que o Modelo Completo;

- $H_{i, t}^{+}$: penalidade por antecipação de uma unidade do item $i$ no período $t$, calculada da mesma forma que o Modelo Completo;

- $W_{k, t}$ : variável binária determinada a partir da solução do Modelo das Ligas $\left(W_{k, t}=1\right.$ indica que o forno é preparado para produzir a liga $k$ no período $t$, caso contrário, $W_{k, t}=$ $0)$.

\section{Variáveis do problema:}

- $X_{i, t}$ : quantidade produzida do item $i$ no período $t$;

- $I_{i, t}^{-}$: quantidade atrasada do item $i$ no final do período $t$,

- $I_{i, t}^{+}$: quantidade estocada do item $i$ no final do período $t$. 
Modelo Matemático das Peças, $P_{k} k=1, \ldots, K$ :

$$
\begin{aligned}
& \text { Minimizar } \\
& \sum_{t=1}^{T} \sum_{i \in S(k)}\left(H_{i, t}^{-} I_{i, t}^{-}+H_{i, t}^{+} I_{i, t}^{+}\right)
\end{aligned}
$$

Sujeito a

$$
\begin{array}{ll}
I_{i, t-1}^{+}-I_{i, t-1}^{-}+X_{i, t}-I_{i, t}^{+}+I_{i, t}^{-}=d_{i, t} & i \in S(k) ; t=1, \ldots, T ; \\
\sum_{i \in S(k)} \rho_{i} X_{i, t} \leq \operatorname{Cap} W_{k, t} & t=1, \ldots, T ; \\
X_{i, t} \geq 0, \text { inteira } & i \in S(k) ; t=1, \ldots, T ; \\
I_{i, t}^{+} \text {e } I_{i, t}^{-} \geq 0, I_{i, 0}^{+}=I_{i, 0}^{-}=0 & i \in S(k) ; t=1, \ldots, T .
\end{array}
$$

A função objetivo (3.9) busca minimizar custos de atraso e de estoque, que foram calculados da mesma forma que o Modelo Completo, e é importante lembrar que após o Modelo $P_{k}$ ter sido resolvido para as ligas $k=1, \ldots, K$, deve ser acrescentado ao valor da função objetivo o valor referente às trocas de ligas dentro de cada dia de programação. As restrições (3.10) são de balanceamento de estoque e as restrições (3.11) são devido à capacidade do forno e asseguram também que itens que utilizam determinada liga só poderão ser produzidos em determinado período se a liga for fundida neste período. As restrições (3.12) representam as condições de não-negatividade da variável inteira $X_{i, t}$ e, por fim, as restrições (3.13) representam as condições de não-negatividade das variáveis $I_{i, t}^{-}$e $I_{i, t}^{+}$.

\subsection{Testes computacionais}

Com o objetivo de determinar a qualidade da abordagem proposta, foram realizados testes com o pacote CPLEX 7.5 (ILOG, 2001) baseados em cenários. A partir de uma carteira de pedidos real de uma fundição, que leva em consideração 383 itens e 19 ligas, foram criados 11 cenários conforme apresentados na Tabela 3.2. Para a criação dos cenários foram consideradas as 5 ligas mais frequentes, ligas com apenas itens atrasados resultando em cenários com 15 e 16 ligas, e a carteira completa com 19 ligas. 
Tabela 3.2: Cenários criados a partir de uma carteira de pedidos real.

\begin{tabular}{|c|c|c|c|c|c|c|}
\hline Cenário & $\begin{array}{c}\text { Nro de } \\
\text { ligas }(K)\end{array}$ & $\begin{array}{c}\text { Nro de } \\
\text { itens (N) }\end{array}$ & $\begin{array}{c}\text { Horizonte de } \\
\text { planejamento }(\mathrm{T})\end{array}$ & $\begin{array}{c}\text { Capacidade } \\
\text { máxima }(\mathbf{K g})\end{array}$ & $\begin{array}{c}\text { Demanda } \\
(\mathrm{Kg})\end{array}$ & Considerações \\
\hline 1 & 5 & 165 & 3 & 10800 & 13863,9 & Considera as 5 ligas mais freqüentes, somente os itens atrasados. \\
\hline 2 & 5 & 165 & 5 & 18000 & 13863,9 & Considera as 5 ligas mais freqüentes, somente os itens atrasados. \\
\hline 3 & 5 & 228 & 3 & 10800 & 20139,45 & Considera as 5 ligas mais freqüentes, todos os itens. \\
\hline 4 & 5 & 293 & 5 & 18000 & 24040,45 & Considera as 5 ligas mais freqüentes, todos os itens. \\
\hline 5 & 16 & 225 & 3 & 10800 & 17211,3 & Considera $100 \%$ dos itens atrasados. \\
\hline 6 & 16 & 225 & 5 & 18000 & 17211,3 & Considera $100 \%$ dos itens atrasados. \\
\hline 7 & 16 & 224 & 3 & 10800 & 15441,5 & Considera aproximadamente $90 \%$ dos itens atrasados. \\
\hline 8 & 16 & 224 & 5 & 18000 & 15441,5 & Considera aproximadamente $90 \%$ dos itens atrasados. \\
\hline 9 & 15 & 224 & 3 & 10800 & 13731,3 & Considera aproximadamente $80 \%$ dos itens atrasados. \\
\hline 10 & 15 & 224 & 5 & 18000 & 13731,3 & Considera aproximadamente $80 \%$ dos itens atrasados. \\
\hline 11 & 19 & 383 & 5 & 18000 & 29311,95 & Carteira completa. \\
\hline
\end{tabular}


Para a fundição, objeto do estudo de caso apresentado neste trabalho, as carteiras de pedidos geralmente estão muito atrasadas e a demanda (em $\mathrm{Kg}$ ) dos itens excede a capacidade de forno disponível em um horizonte de planejamento de 5 dias. Em vista disso, a maior parte dos cenários criados considera carteiras com itens atrasados. Para a obtenção das carteiras com aproximadamente $90 \%$ e $80 \%$ dos itens atrasados, foram retirados itens menos atrasados procurando não diminuir o número total de itens presentes na carteira. Carteiras que consideram também os itens não atrasados foram criadas, e são representadas pelos Cenários 3 e 4. Para todos os cenários foram consideradas no máximo 10 cargas de forno por dia $(L)$ e capacidade do forno (Cap) de $360 \mathrm{Kg}$.

Para a realização dos testes foi utilizado um Pentium 4, 2,8 GHz com 512 MB de memória RAM. Ao rodarmos no CPLEX o Modelo Completo para cada cenário, por uma hora, foram obtidos os seguintes resultados:

Tabela 3.3: Resultado do CPLEX para o Modelo Completo.

\begin{tabular}{|c|c|c|c|c|c|c|c|c|}
\hline Cenário & $F o_{C}$ & $\mathbf{M l}$ & GapFo (\%) & $N f_{C}$ & $N f 360_{C}$ & $N f 360 u_{C}$ & $N f 120_{C}$ & $S u b_{C}$ \\
\hline \hline 1 & 174825,94 & 166370,63 & 4,84 & 30 & 0 & 0 & 2 & 399,30 \\
\hline 2 & 205883,49 & 166347,75 & 19,20 & 44 & 2 & 1 & 4 & 1976,10 \\
\hline 3 & 205391,08 & 192921,12 & 6,07 & 30 & 0 & 0 & 0 & 90,10 \\
\hline 4 & 295219,09 & 227727,36 & 22,86 & 50 & 0 & 0 & 0 & 96,80 \\
\hline 5 & 413734,10 & 327140,49 & 20,93 & 30 & 0 & 0 & 5 & 1134,80 \\
\hline 6 & 504771,50 & 366684,64 & 27,36 & 50 & 0 & 0 & 15 & 4522,30 \\
\hline 7 & 346141,10 & 290092,61 & 16,19 & 30 & 0 & 0 & 3 & 936,90 \\
\hline 8 & 461056,49 & 309128,63 & 32,95 & 50 & 2 & 2 & 11 & 3522,35 \\
\hline 9 & 286321,74 & 254066,46 & 11,27 & 30 & 0 & 0 & 4 & 1048,75 \\
\hline 10 & 370755,30 & 258528,09 & 30,27 & 50 & 6 & 6 & 11 & 5398,80 \\
\hline 11 & 615244,39 & 481605,56 & 21,72 & 50 & 1 & 0 & 8 & 2359,55 \\
\hline
\end{tabular}

A coluna GapFo indica a diferença percentual entre a melhor solução $\left(F o_{C}\right)$ e o limitante inferior encontrado pelo CPLEX (Ml) e foi calculada da forma:

$$
\frac{F o_{C}-M l}{F o_{C}} * 100
$$

A coluna $N f_{C}$ representa o número de preparações de fornos $\left(W_{k, t}=1\right)$, a coluna $N f 360_{C}$ indica o número de fornadas para as quais houve preparação, mas que não foram utilizadas, a coluna $N f 360 u_{C}$ indica o número de fornadas que não foram utilizadas no último período, que na prática, poderiam deixar de ser feitas sem alterar o valor da 
função objetivo, $N f 120_{C}$ indica o número de fornadas com utilização de menos de $33 \%$ do forno e, por fim, a coluna $S u b_{C}$ indica a quantidade total (em kg) de subutilização das fornadas, considerando inclusive as fornadas para as quais houve preparação e não foram utilizadas, ou seja, representa a má utilização do forno. Na prática, a subutilização do forno é evitada ao máximo, devido ao prejuízo gerado por causa da energia contratada.

É possível verificar que para a maioria dos cenários a solução ainda pode estar muito longe da solução ótima, incentivando assim a utilização de heurísticas. Ainda podemos observar que a subutilização do forno é muito alta, em média 1953,25 Kg para cada cenário, o que indica que pode ser feito uma melhoria no sentido de diminuir esses valores. Para tanto, foi realizado um estudo levando em consideração, além da penalidade pelo atraso de liga, a penalidade pela antecipação de liga, a qual não é representada no Modelo Completo.

As subseções seguintes apresentam testes para a definição do melhor critério para a determinação de Kaux e é feita a análise do problema quando considera-se a penalidade pela antecipação de liga $\left(H_{k, t}^{+}\right)$no Modelo das Ligas.

\subsubsection{Abordagem sem penalidade para antecipação de liga}

Inicialmente foi feita a análise em relação ao melhor critério para a subdivisão de cada liga $k$ no Modelo das Ligas, resultando assim em Kaux ligas. Esta análise inicial não levou em consideração a penalidade pela antecipação de liga, ou seja, considera $H_{k, t}^{+}=0$, para que a compatibilidade com o Modelo Completo fosse mantida.

O Modelo das Ligas foi executado no CPLEX até que a solução ótima fosse obtida ou o tempo de execução atingisse 20 minutos. Apenas alguns cenários pertencentes ao Critério 1, para a abordagem sem penalidade, não alcançaram a otimalidade neste prazo e são apresentadas na Tabela 3.4. 
Tabela 3.4: Cenários do Critério 1 em que o Modelo das Ligas não obteve solução ótima.

\begin{tabular}{|c|c|}
\hline Cenário & $\mathrm{GapFo}_{\mathbf{l}} \mathbf{( \% )}$ \\
\hline \hline 2 & 6,67 \\
\hline 4 & 5,24 \\
\hline 6 & 5,52 \\
\hline 8 & 8,21 \\
\hline 10 & 7,75 \\
\hline 11 & 5,36 \\
\hline
\end{tabular}

A coluna $G a p F o_{l}$ indica a diferença percentual entre a melhor solução encontrada para o Modelo das Ligas e o limitante inferior encontrado pelo CPLEX. Podemos verificar que mesmo não atingindo a otimalidade, os resultados são bons. O tempo restante para completar 1 hora foi dividido igualmente entre cada um dos subproblemas para cálculo das peças. Por exemplo, caso sejam consideradas 5 ligas e o Problema das Ligas tenha chegado na solução ótima em 5 minutos, cada Modelo $P_{k}, k=1, \ldots, 5$ é executado por 11 minutos.

Na Tabela 3.5 são apresentados os resultados para cada um dos critérios discutidos na Seção 3.2: 
Tabela 3.5: Resultados para a abordagem de decomposição sem penalidade.

\begin{tabular}{|c|c|c|c|c|c|c|c|c|c|}
\hline \multirow[b]{2}{*}{ Cenário } & \multicolumn{3}{|c|}{ Critério 1} & \multicolumn{3}{|c|}{ Critério 2} & \multicolumn{3}{|c|}{ Critério 3} \\
\hline & $F o_{D s}$ & $M G a p_{D s}(\%)$ & GapFo $_{D s-C}(\%)$ & $F o_{D s}$ & $M G a p_{D s}(\%)$ & GapFo $_{D s-C}(\%)$ & $F o_{D s}$ & $M G a p_{D s}(\%)$ & GapFo $_{D s-C}(\%)$ \\
\hline 1 & 195601,05 & 0,75 & 10,62 & 403065,95 & 0,07 & 56,63 & 226804,20 & 0,01 & 22,92 \\
\hline 2 & 201699,50 & 1,00 & $-2,07$ & 403097,85 & 0,07 & 48,92 & 226834,40 & 0,03 & 9,24 \\
\hline 3 & 218454,01 & 0,54 & 5,98 & 669497,36 & 7,64 & 69,32 & 348307,89 & 0,46 & 41,03 \\
\hline 4 & 263597,75 & 2,32 & $-12,00$ & 891455,28 & 4,34 & 66,88 & 491052,70 & 0,13 & 39,88 \\
\hline 5 & 351980,60 & 0,80 & $-17,54$ & 624856,43 & 1,00 & 33,79 & 437951,98 & 0,03 & 5,53 \\
\hline 6 & 419006,95 & 1,73 & $-20,47$ & 684330,90 & 0,11 & 26,24 & 482409,45 & 0,06 & $-4,64$ \\
\hline 7 & 316955,39 & 0,80 & $-9,21$ & 576441,48 & 1,00 & 39,95 & 383580,23 & 0,01 & 9,76 \\
\hline 8 & 387914,19 & 3,54 & $-18,86$ & 604118,75 & 0,11 & 23,68 & 404924,25 & 0,11 & $-13,86$ \\
\hline 9 & 278900,60 & 0,80 & $-2,66$ & 529368,83 & 1,00 & 45,91 & 364871,98 & 0,03 & 21,53 \\
\hline 10 & 301623,20 & 1,02 & $-22,92$ & 565997,30 & 0,10 & 34,50 & 371432,75 & 0,05 & 0,18 \\
\hline 11 & 544919,59 & 2,14 & $-12,91$ & 1336939,98 & 4,34 & 53,98 & 873440,61 & 1,34 & 29,56 \\
\hline Média & & & $-9,28$ & & & 45,44 & & & 14,65 \\
\hline
\end{tabular}

continua na próxima página 
Tabela 3.5: Resultados para a abordagem de decomposição sem penalidade (continuação).

\begin{tabular}{|c|c|c|c|c|c|c|}
\hline & \multicolumn{3}{|c|}{ Critério 4} & \multicolumn{3}{|c|}{ Critério 5} \\
\hline Cenário & $F o_{D s}$ & $M G a p_{D s}(\%)$ & GapFo $_{D s-C}(\mathbf{\%})$ & $F o_{D s}$ & $M G a p_{D s}(\boldsymbol{\%})$ & $G a p F o_{D s-C}(\boldsymbol{\%})$ \\
\hline 1 & 202283,10 & 0,06 & 13,57 & 184856,85 & 2,07 & 5,43 \\
\hline 2 & 205628,20 & 0,37 & $-0,12$ & 191840,90 & 3,21 & $-7,32$ \\
\hline 3 & 220840,18 & 1,99 & 7,00 & 206380,27 & 1,55 & 0,48 \\
\hline 4 & 270597,21 & 7,44 & $-9,10$ & 254936,45 & 5,24 & $-15,80$ \\
\hline 5 & 376343,59 & 0,22 & $-9,94$ & 349804,30 & 0,22 & $-18,28$ \\
\hline 6 & 426406,35 & 0,92 & $-18,38$ & 420628,10 & 1,34 & $-20,00$ \\
\hline 7 & 338376,59 & 0,22 & $-2,29$ & 312409,50 & 0,22 & $-10,80$ \\
\hline 8 & 372165,60 & 1,54 & $-23,88$ & 350359,35 & 0,92 & $-31,60$ \\
\hline 9 & 300598,79 & 0,22 & 4,75 & 276724,30 & 0,22 & $-3,47$ \\
\hline 10 & 316425,15 & 5,74 & $-17,17$ & 293627,55 & 1,38 & $-26,27$ \\
\hline 11 & 558835,79 & 0,67 & $-10,09$ & 530537,80 & 1,70 & $-15,97$ \\
\hline Média & & & $-5,97$ & & & $-13,05$ \\
\hline
\end{tabular}


A coluna $F o_{D s}$ representa o valor da função objetivo total, ou seja, considera os valores das funções objetivo de cada Problema $P_{k}$ e as trocas de ligas. Na execução dos testes, independente de cenários e critérios, o CPLEX obteve a solução ótima para $78,91 \%$ dos Problemas $P_{k}$. Para cada cenário, foram analisados todos os Problemas $P_{k}$ para os quais não foi obtida a solução ótima e, a maior diferença percentual entre a melhor solução obtida e o limitante inferior encontrado pelo CPLEX, é representada pela coluna $M G a p_{D s}$. É possível notar que para a maioria dos cenários a solução obtida pela abordagem de decomposição está bem perto da solução ótima.

A coluna GapFo $_{D s-C}$ é calculada da forma:

$$
\frac{F o_{D s}-F o_{C}}{F o_{D s}} * 100
$$

e representa a diferença percentual entre a solução da abordagem proposta $\left(F o_{D s}\right)$ e o resultado obtido para o Modelo Completo $\left(F_{O_{C}}\right)$.

Para os critérios 1, 4 e 5, os resultados obtidos na maior parte dos cenários foram melhores que as soluções geradas pelo CPLEX em 1 hora. No geral, o melhor critério é o 5 .

Na Tabela 3.6 são apresentados os resultados em relação à utilização do forno.

Tabela 3.6: Resultados referentes à utilização do forno.

\begin{tabular}{|c|c|c|c|c|c|c|}
\cline { 2 - 7 } \multicolumn{1}{c|}{} & \multicolumn{6}{c|}{ Critério 1} \\
\hline Cenário & $N f_{D s}$ & $N f 360_{D s}$ & $N f 360 u_{D s}$ & $N f 120_{D s}$ & $S u b_{D s}$ & $\begin{array}{c}G a p S u b_{D s-C} \\
(\%)\end{array}$ \\
\hline \hline 1 & 30 & 1 & 1 & 3 & 1204,35 & 66,85 \\
\hline 2 & 50 & 8 & 6 & 4 & 4136,30 & 52,23 \\
\hline 3 & 30 & 0 & 0 & 0 & 6,80 & $-1225,00$ \\
\hline 4 & 50 & 2 & 1 & 0 & 852,45 & 88,64 \\
\hline 5 & 30 & 0 & 0 & 2 & 669,85 & $-69,41$ \\
\hline 6 & 50 & 2 & 1 & 6 & 2309,25 & $-95,83$ \\
\hline 7 & 30 & 0 & 0 & 3 & 931,65 & $-0,56$ \\
\hline 8 & 50 & 5 & 4 & 6 & 3479,55 & $-1,23$ \\
\hline 9 & 30 & 0 & 0 & 2 & 669,85 & $-56,56$ \\
\hline 10 & 50 & 7 & 5 & 8 & 4699,55 & $-14,88$ \\
\hline 11 & 50 & 3 & 2 & 9 & 3330,05 & 29,14 \\
\hline Média & & & & \multicolumn{5}{c|}{ continua na próxima página } \\
\hline
\end{tabular}


Tabela 3.6: Resultados referentes à utilização do forno (continuação).

\begin{tabular}{|c|c|c|c|c|c|c|c|c|c|c|c|c|}
\hline \multirow[b]{2}{*}{ Cenário } & \multicolumn{6}{|c|}{ Critério 2} & \multicolumn{6}{|c|}{ Critério 3} \\
\hline & $N f_{D s}$ & $N f 360_{D s}$ & $N f 360 u_{D s}$ & $N f 120_{D s}$ & $S u b_{D s}$ & $\begin{array}{c}G a p S u b_{D s-C} \\
\mathbf{( \% )}\end{array}$ & $N f_{D s}$ & $N f 360_{D s}$ & $N f 360 u_{D s}$ & $N f 120_{D s}$ & $S u b_{D s}$ & $\begin{array}{c}G a p S u b_{D s-C} \\
(\%)\end{array}$ \\
\hline 1 & 30 & 0 & 0 & 1 & 416,10 & 4,04 & 30 & 0 & 0 & 0 & 142,85 & $-179,52$ \\
\hline 2 & 40 & 0 & 0 & 1 & 536,10 & $-268,61$ & 40 & 0 & 0 & 1 & 536,10 & $-268,61$ \\
\hline 3 & 30 & 0 & 0 & 0 & 18,25 & $-393,70$ & 30 & 0 & 0 & 0 & 7,75 & $-1062,58$ \\
\hline 4 & 50 & 0 & 0 & 0 & 114,60 & 15,53 & 50 & 0 & 0 & 1 & 443,85 & 78,19 \\
\hline 5 & 30 & 0 & 0 & 0 & 130,75 & $-767,92$ & 30 & 0 & 0 & 1 & 387,15 & $-193,12$ \\
\hline 6 & 50 & 0 & 0 & 8 & 2180,70 & $-107,38$ & 50 & 0 & 0 & 5 & 1395,30 & $-224,11$ \\
\hline 7 & 30 & 0 & 0 & 0 & 119,75 & $-682,38$ & 30 & 0 & 0 & 1 & 352,60 & $-165,71$ \\
\hline 8 & 50 & 0 & 0 & 10 & 2558,50 & $-37,67$ & 50 & 0 & 0 & 10 & 2558,50 & $-37,67$ \\
\hline 9 & 30 & 0 & 0 & 0 & 130,75 & $-702,10$ & 30 & 0 & 0 & 1 & 387,15 & $-170,89$ \\
\hline 10 & 44 & 0 & 0 & 8 & 2108,70 & $-156,03$ & 44 & 0 & 0 & 8 & 2108,70 & $-156,03$ \\
\hline 11 & 50 & 0 & 0 & 0 & 114,60 & $-1958,94$ & 50 & 0 & 0 & 3 & 785,20 & $-200,50$ \\
\hline Média & & & & & 766,25 & $-459,56$ & & & & & 827,74 & $-234,60$ \\
\hline
\end{tabular}

continua na próxima página 
Tabela 3.6: Resultados referentes à utilização do forno (continuação).

\begin{tabular}{|c|c|c|c|c|c|c|c|c|c|c|c|c|}
\hline \multirow[b]{2}{*}{ Cenário } & \multicolumn{6}{|c|}{ Critério 4} & \multicolumn{6}{|c|}{ Critério 5} \\
\hline & $N f_{D s}$ & $N f 360_{D s}$ & $N f 360 u_{D s}$ & $N f 120_{D s}$ & $S u b_{D s}$ & $\begin{array}{c}G a p S u b_{D s-C} \\
(\%)\end{array}$ & $N f_{D s}$ & $N f 360_{D s}$ & $N f 360 u_{D s}$ & $N f 120_{D s}$ & $S u b_{D s}$ & $\begin{array}{c}G a p S u b_{D s-C} \\
(\%)\end{array}$ \\
\hline 1 & 30 & 0 & 0 & 1 & 370,60 & $-7,74$ & 30 & 1 & 1 & 1 & 722,45 & 44,73 \\
\hline 2 & 47 & 6 & 6 & 3 & 3056,10 & 35,34 & 50 & 5 & 3 & 7 & 4141,30 & 52,28 \\
\hline 3 & 30 & 0 & 0 & 0 & 40,45 & $-122,74$ & 30 & 0 & 0 & 0 & 62,90 & $-43,24$ \\
\hline 4 & 50 & 0 & 0 & 0 & 139,00 & 30,36 & 50 & 2 & 1 & 0 & 882,40 & 89,03 \\
\hline 5 & 30 & 0 & 0 & 2 & 561,75 & $-102,01$ & 30 & 0 & 0 & 3 & 833,40 & $-36,17$ \\
\hline 6 & 50 & 0 & 0 & 6 & 1627,55 & $-177,86$ & 50 & 2 & 1 & 7 & 2506,65 & $-80,41$ \\
\hline 7 & 30 & 0 & 0 & 3 & 823,80 & $-13,73$ & 30 & 0 & 0 & 3 & 799,00 & $-17,26$ \\
\hline 8 & 50 & 1 & 1 & 10 & 2849,45 & $-23,62$ & 50 & 3 & 3 & 8 & 3156,35 & $-11,60$ \\
\hline 9 & 30 & 0 & 0 & 2 & 562,00 & $-86,61$ & 30 & 0 & 0 & 3 & 833,40 & $-25,84$ \\
\hline 10 & 50 & 3 & 3 & 10 & 4268,70 & $-26,47$ & 50 & 4 & 3 & 11 & 4268,70 & $-26,47$ \\
\hline 11 & 50 & 0 & 0 & 5 & 1228,70 & $-92,04$ & 50 & 1 & 1 & 5 & 1542,50 & $-52,97$ \\
\hline Média & & & & & 1411,65 & $-53,38$ & & & & & 1795,37 & $-9,81$ \\
\hline
\end{tabular}


A coluna $N f_{D s}$ representa o número de preparações de fornos $\left(W_{k, t}=1\right), N f 360_{D s}$ indica o número de fornadas para a qual houve preparação, mas que não foram utilizadas, a coluna $N f 360 u_{D s}$ indica o número de fornadas que não foram utilizadas no último período, que na prática, poderiam deixar de ser feitas sem alteração no valor da função objetivo, $N f 120_{D s}$ indica o número de fornadas com utilização de menos de $33 \%$ do forno, a coluna $S u b_{D s}$ indica a quantidade (em Kg) de forno não utilizado, considerando inclusive as fornadas para as quais houve preparação e não foram utilizadas e, por fim, a coluna $\operatorname{GapSub}_{D s-C}$ foi calculada da forma:

$$
\frac{S u b_{D s}-S u b_{C}}{S u b_{D s}} * 100
$$

Em grande parte dos cenários, independente do critério, a abordagem proposta subutilizou menos o forno que o Modelo Completo. Nos Critérios 2 e 3, não houve fornos com preparação que não foram utilizados e nos Critérios 1, 4 e 5, a quantidade de fornadas com utilização de menos de $33 \%$ do forno foi menor que para o Modelo Completo. Mesmo assim, para o Critério 2, que aproveitou melhor o forno, a quantidade em $\mathrm{Kg}$ de forno subutilizado ainda é muito grande.

Uma forma para evitar a subutilização dos fornos é considerar uma penalidade pela quantidade do forno que não foi utilizada, ou analogamente, ao considerar que sempre são fundidos Cap Kg por fornada, podemos considerar uma penalidade para a quantidade de liga que viraria lingote, ou seja, quantidade de liga fundida e não aproveitada para fabricação das peças. Esta nova abordagem é apresentada na próxima subseção.

\subsubsection{Abordagem com penalidade para antecipação de liga}

Para diminuir a subutilização dos fornos, uma alternativa foi considerar uma penalidade pela antecipação de liga, representando assim a subutilização do forno. Após testes foram obtidos os resultados apresentados na Tabela 3.7. 
Tabela 3.7: Resultados referentes à utilização do forno.

\begin{tabular}{|c|c|c|c|c|c|c|c|c|c|c|c|c|}
\hline & \multicolumn{4}{|c|}{ Critério 1} & \multicolumn{4}{|c|}{ Critério 2} & \multicolumn{4}{|c|}{ Critério 3} \\
\hline Cenário & $N f_{D c}$ & $S u b_{D c}$ & $G a p S u b_{D c-C}$ & $G_{a p S u b_{D c-D s}}$ & $N f_{D c}$ & $S u b_{D c}$ & $\operatorname{GapSub}_{D c-C}$ & $G_{a p S u b_{D c-D s}}$ & $N f_{D c}$ & $S u b_{D c}$ & $G_{a p S u b_{D c-C}}$ & ${\operatorname{Gap} S u b_{D c-D s}}$ \\
\hline 1 & 22 & 108,75 & $-267,17$ & $-1007,45$ & 30 & 77,60 & $-414,56$ & $-436,21$ & 30 & 77,70 & $-413,90$ & $-83,85$ \\
\hline 3 & 30 & 110,80 & 18,68 & 93,86 & 30 & 9,25 & $-874,05$ & $-97,30$ & 30 & 7,75 & $-1062,58$ & 0,00 \\
\hline 4 & 43 & 123,50 & 21,62 & $-590,24$ & 50 & 33,30 & $-190,69$ & $-244,14$ & 50 & 126,20 & 23,30 & $-251,70$ \\
\hline 7 & 19 & 61,35 & $-1427,14$ & $-1418,58$ & 30 & 72,05 & $-1200,35$ & $-66,20$ & 30 & 72,15 & $-1198,54$ & $-388,70$ \\
\hline 8 & 19 & 61,40 & $-5636,73$ & $-5567,02$ & 34 & 120,00 & $-2835,29$ & $-2032,08$ & 34 & 120,10 & $-2832,85$ & $-2030,31$ \\
\hline 9 & 14 & 0,75 & $-139733,33$ & $-89213,33$ & 29 & 53,10 & $-1875,05$ & $-146,23$ & 29 & 53,55 & $-1858,45$ & $-622,97$ \\
\hline 10 & 14 & 1,40 & $-385528,57$ & $-335582,14$ & 29 & 53,40 & $-10010,11$ & $-3848,88$ & 29 & 53,50 & $-9991,21$ & $-3841,50$ \\
\hline 11 & 45 & 122,80 & $-1821,46$ & $-2611,77$ & 50 & 33,30 & $-6985,74$ & $-244,14$ & 50 & 103,35 & $-2183,07$ & $-659,75$ \\
\hline
\end{tabular}


Tabela 3.7: Resultados referentes à utilização do forno (continuação).

\begin{tabular}{|c|c|c|c|c|c|c|c|c|}
\cline { 2 - 9 } \multicolumn{1}{c|}{} & \multicolumn{9}{|c|}{ Critério 4} & \multicolumn{4}{c|}{ Critério 5} \\
\hline Cenário & $N f_{D c}$ & $S u b_{D c}$ & $G a p S u b_{D c-C}$ & $G a p S u b_{D c-D s}$ & $N f_{D c}$ & $S u b_{D c}$ & GapSub $b_{D c-C}$ & $G_{a p S u b_{D c-D s}}$ \\
\hline \hline 1 & 30 & 103,85 & $-284,50$ & $-256,86$ & 30 & 100,85 & $-295,93$ & $-616,36$ \\
\hline 2 & 33 & 137,15 & $-1340,83$ & $-2128,29$ & 33 & 138,45 & $-1327,30$ & $-2891,19$ \\
\hline 3 & 30 & 111,50 & 19,19 & 63,72 & 30 & 87,20 & $-3,33$ & 27,87 \\
\hline 4 & 50 & 140,40 & 31,05 & 1,00 & 50 & 120,25 & 19,50 & $-633,80$ \\
\hline 5 & 30 & 88,50 & $-1182,26$ & $-534,75$ & 30 & 131,20 & $-764,94$ & $-535,21$ \\
\hline 6 & 36 & 168,35 & $-2586,25$ & $-866,77$ & 36 & 161,35 & $-2702,79$ & $-1453,55$ \\
\hline 7 & 30 & 76,35 & $-1127,11$ & $-978,98$ & 30 & 88,40 & $-959,84$ & $-803,85$ \\
\hline 8 & 31 & 91,25 & $-3760,11$ & $-3022,68$ & 31 & 91,40 & $-3753,77$ & $-3353,34$ \\
\hline 9 & 27 & 52,50 & $-1897,62$ & $-970,48$ & 27 & 47,40 & $-2112,55$ & $-1658,23$ \\
\hline 10 & 27 & 60,35 & $-8845,82$ & $-6973,24$ & 27 & 53,35 & $-10019,59$ & $-7901,31$ \\
\hline 11 & 50 & 168,65 & $-1299,08$ & $-628,55$ & 50 & 116,05 & $-1933,22$ & $-1229,17$ \\
\hline Média & & 108,99 & $-2024,85$ & $-1481,44$ & & 103,26 & $-2168,52$ & $-1913,47$ \\
\hline
\end{tabular}


A coluna $N f_{D c}$ representa o número de preparações de fornos $\left(W_{k, t}=1\right)$, a coluna $G a p S u b_{D c-C}$ é calculada da forma:

$$
\frac{S u b_{D c}-S u b_{C}}{S u b_{D c}} * 100
$$

e $G a p S u b_{D c-D s}$ é:

$$
\frac{S u b_{D c}-S u b_{D s}}{S u b_{D c}} * 100 .
$$

Nesta abordagem houve menos preparações para fornos e não houve fornadas com preparação sem que tivessem sido utilizadas $\left(N f 360_{D c}=0\right)$, nem fornadas com utilização de menos de $33 \%$ de sua capacidade $\left(N f 120_{D c}=0\right)$. Tanto em relação à abordagem descrita na subseção anterior, quanto em relação ao Modelo Completo resolvido pelo CPLEX em 1 hora, esta abordagem apresenta um aproveitamento muito melhor do forno. Na abordagem anterior, o Critério 2, que foi o critério que melhor aproveitou o forno, subutilizou em média o equivalente a pouco mais de 2 fornadas para cada cenário, enquanto esta abordagem subutiliza em média aproximadamente $1 / 5$ de forno para cada cenário.

Considerando os cenários conjuntamente, a subutilização para cada critério é resumida na Tabela 3.8.

Tabela 3.8: Subutilização do forno independente de cenários.

\begin{tabular}{|c|c|c|}
\hline Critério & TotSub $_{D s}$ & TotSub $_{D c}$ \\
\hline \hline 1 & 22289,65 & 918,90 \\
\hline 2 & 8428,80 & 816,80 \\
\hline 3 & 9105,15 & 979,40 \\
\hline 4 & 15528,10 & 1198,85 \\
\hline 5 & 19749,05 & 1135,90 \\
\hline
\end{tabular}

A coluna $\operatorname{TotSub}_{D s}$ representa o total de subutilização de fornos (em $\mathrm{Kg}$ ) para a abordagem de decomposição sem penalidade para antecipação de liga e a coluna $T o t S u b_{D c}$ para a abordagem com penalidade. Nota-se considerável melhora na utilização do forno e, consequentemente, melhor aproveitamento da energia elétrica contratada pela fundição.

Na Tabela 3.9 são apresentados resultados para a análise da qualidade da solução, de acordo com cada critério de definição do Kaux descrito na seção anterior. 
Tabela 3.9: Comparação da abordagem de decomposição com penalidade.

\begin{tabular}{|c|c|c|c|c|c|c|c|c|}
\hline & \multicolumn{4}{|c|}{ Critério 1} & \multicolumn{4}{|c|}{ Critério 2} \\
\hline Cenário & $F o_{D c}$ & $\begin{array}{c}M G a p_{D c} \\
(\%)\end{array}$ & $\begin{array}{c}G a p F o_{D c-C} \\
(\%)\end{array}$ & $\begin{array}{c}G a p F o_{D c-D s} \\
(\%)\end{array}$ & $F o_{D c}$ & $\begin{array}{c}M G a p_{D c} \\
(\%)\end{array}$ & $\begin{array}{c}G a p F o_{D c-C} \\
(\%)\end{array}$ & $\begin{array}{c}G a p F o_{D c-D s} \\
(\%)\end{array}$ \\
\hline 1 & 299892,10 & 0,08 & 41,70 & 34,78 & 401525,90 & 2,19 & 56,46 & $-0,38$ \\
\hline 2 & 512940,90 & 0,09 & 59,86 & 60,68 & 428660,25 & 1,45 & 51,97 & 5,96 \\
\hline 3 & 270364,31 & 0,13 & 24,03 & 19,20 & 648259,32 & 2,7 & 68,32 & $-3,28$ \\
\hline 4 & 312442,12 & 1,05 & 5,51 & 15,63 & 865213,79 & 41,2 & 65,88 & $-3,03$ \\
\hline 5 & 522965,24 & 0,09 & 20,89 & 32,70 & 610921,29 & 2,23 & 32,28 & $-2,28$ \\
\hline 6 & 918841,12 & 0,09 & 45,06 & 54,40 & 740412,67 & 1,45 & 31,83 & 7,57 \\
\hline 7 & 497654,24 & 0,09 & 30,45 & 36,31 & 573808,29 & 2,23 & 39,68 & $-0,46$ \\
\hline 8 & 842658,77 & 0,09 & 45,29 & 53,97 & 696246,87 & 1,45 & 33,78 & 13,23 \\
\hline 9 & 486790,94 & 0,08 & 41,18 & 42,71 & 540601,44 & 2,19 & 47,04 & 2,08 \\
\hline 10 & 833400,77 & 0,09 & 55,51 & 63,81 & 663484,67 & 1,45 & 44,12 & 14,69 \\
\hline 11 & 751765,33 & 1,28 & 18,16 & 27,51 & 1310698,49 & 41,2 & 53,06 & $-2,00$ \\
\hline Média & & & 35,24 & 40,15 & & & 47,67 & 2,92 \\
\hline
\end{tabular}

continua na próxima página 
Tabela 3.9: Comparação da abordagem de decomposição com penalidade (continuação).

\begin{tabular}{|c|c|c|c|c|c|c|c|c|}
\hline \multirow[b]{2}{*}{ Cenário } & \multicolumn{4}{|c|}{ Critério 3} & \multicolumn{4}{|c|}{ Critério 4} \\
\hline & $F o_{D c}$ & $\begin{array}{c}M G a p_{D c} \\
(\%)\end{array}$ & $\begin{array}{c}\text { GapF } o_{D c-C} \\
(\%)\end{array}$ & $\begin{array}{c}\text { GapFo } o_{D c-D s} \\
(\%)\end{array}$ & $F o_{D c}$ & $\begin{array}{c}M G a p_{D c} \\
(\%)\end{array}$ & $\begin{array}{c}\text { GapFo } o_{D c-C} \\
(\%)\end{array}$ & $\begin{array}{c}\text { GapF } o_{D c-D s} \\
(\%)\end{array}$ \\
\hline 1 & 217186,65 & 2,19 & 19,50 & $-4,43$ & 207644,15 & 1,69 & 15,81 & 2,58 \\
\hline 2 & 244322,90 & 1,45 & 15,73 & 7,16 & 251745,70 & 1,56 & 18,22 & 18,32 \\
\hline 3 & 348307,89 & 0,46 & 41,03 & 0,00 & 236214,80 & 0,28 & 13,05 & 6,51 \\
\hline 4 & 443559,80 & 1,34 & 33,44 & $-10,71$ & 303857,05 & 1,62 & 2,84 & 10,95 \\
\hline 5 & 404744,14 & 2,23 & $-2,22$ & $-8,20$ & 385903,69 & 0,56 & $-7,21$ & 2,48 \\
\hline 6 & 534237,42 & 1,45 & 5,52 & 9,70 & 533675,57 & 2,24 & 5,42 & 20,10 \\
\hline 7 & 367716,94 & 2,23 & 5,87 & $-4,31$ & 345950,09 & 1,34 & $-0,06$ & 2,19 \\
\hline 8 & 490157,42 & 1,45 & 5,94 & 17,39 & 491935,67 & 1,48 & 6,28 & 24,35 \\
\hline 9 & 334438,14 & 2,23 & 14,39 & $-9,10$ & 321165,69 & 0,56 & 10,85 & 6,40 \\
\hline 10 & 457309,42 & 1,45 & 18,93 & 18,78 & 462315,57 & 2,24 & 19,80 & 31,56 \\
\hline 11 & 840586,48 & 1,34 & 26,81 & $-3,91$ & 641212,41 & 2,23 & 4,05 & 12,85 \\
\hline Média & & & 16,81 & 1,12 & & & 8,09 & 12,57 \\
\hline
\end{tabular}

continua na próxima página 
Tabela 3.9: Comparação da abordagem de decomposição com penalidade (continuação).

\begin{tabular}{|c|c|c|c|c|}
\cline { 2 - 5 } \multicolumn{1}{c|}{} & \multicolumn{4}{|c|}{ Critério 5} \\
\hline Cenário & $F o_{D c}$ & $\begin{array}{c}M G a p_{D c} \\
\mathbf{( \% )}\end{array}$ & $\begin{array}{c}G a p F o_{D c-C} \\
\mathbf{( \% )}\end{array}$ & $\begin{array}{c}G a p F o_{D c-D s} \\
\mathbf{( \% )}\end{array}$ \\
\hline \hline 1 & 173458,80 & 1,85 & $-0,79$ & $-6,57$ \\
\hline 2 & 217370,10 & 1,34 & 5,28 & 11,74 \\
\hline 3 & 199740,60 & 0,85 & $-2,83$ & $-3,32$ \\
\hline 4 & 248499,62 & 4,55 & $-18,80$ & $-2,59$ \\
\hline 5 & 364590,89 & 0,17 & $-13,48$ & 4,06 \\
\hline 6 & 509814,77 & 1,12 & 0,99 & 17,49 \\
\hline 7 & 333181,34 & 1,85 & $-3,89$ & 6,23 \\
\hline 8 & 478693,92 & 1,34 & 3,68 & 26,81 \\
\hline 9 & 298140,89 & 0,17 & 3,96 & 7,18 \\
\hline 10 & 438454,77 & 1,12 & 15,44 & 33,03 \\
\hline 11 & 576020,83 & 1,55 & $-6,81$ & 7,90 \\
\hline Média & & & $-1,57$ & 9,27 \\
\hline
\end{tabular}

No geral, independente de cenários e critérios, o CPLEX obteve a solução ótima para $58,11 \%$ dos Problemas $P_{k}$. Para cada cenário, foram analisados todos os Problemas $P_{k}$ que não chegaram na solução ótima e a maior diferença percentual entre a melhor solução obtida e o limitante inferior encontrado pelo CPLEX, é representada pela coluna $M G a p_{D c}$. É possível notar que para a maioria dos cenários a solução obtida pela abordagem de decomposição está bem perto da solução ótima.

A coluna $G_{a p F} o_{D c-C}$ é calculada da forma:

$$
\frac{F o_{D c}-F o_{C}}{F o_{D c}} * 100
$$

e $G a p F O_{D c-D s}$ é:

$$
\frac{F o_{D c}-F o_{D s}}{F o_{D c}} * 100
$$

Pode-se concluir que apesar de apresentar valores para a função objetivo, no geral, piores que a abordagem que não considera penalidade por antecipação da liga, o Critério 5 consegue obter resultados melhores que o CPLEX rodando por 1 hora para o Modelo Completo em aproximadamente 50\% dos cenários. Mesmo que para este cenário, a queda da subutilização dos fornos não seja a maior, conforme apresentado na Tabela 3.8, a melhora no valor da função objetivo nos leva a adotar este critério. 


\subsection{Considerações finais}

Primeiramente foi apresentada a estratégia de decomposição do Modelo Completo em dois subproblemas de dimensionamento de lotes. O primeiro é representado pelo Modelo Matemático das Ligas que determina o número de vezes que cada liga deve ser feita no período, e então é gerada a sequência de fusão das ligas. Já o segundo, representado pelo Modelo Matemático das Peças, determina para cada liga $k$ a quantidade a ser produzida de cada item $i \in S(k)$ nos períodos com preparação para a liga.

Para o Modelo das Ligas é possível agrupar os itens pertencentes à determinada liga de formas diversas, logo foram definidos e testados 5 critérios diferentes. Além disso, foi possível considerar uma penalidade para antecipação de liga que não está presente no Modelo Completo.

Os testes realizados foram resolvidos no CPLEX e se basearam em 11 cenários. Para a abordagem sem penalidade para antecipação de liga, as soluções obtidas foram muito boas, com resultados melhores que o Modelo Completo resolvido pelo CPLEX por 1 hora tanto em relação ao valor da função objetivo, quanto em relação à utilização do forno. No entanto, o nível de subutilização dos fornos continuou elevado.

A alternativa foi considerar a penalidade para a antecipação de liga. Com esta abordagem o grau de subutilização dos fornos caiu drasticamente e, em especial, para o Critério 5, o valor da função objetivo, em média, foi melhor que o valor obtido pelo CPLEX para o Modelo Completo. Isto nos levou a adotar este critério no desenvolvimento da heurística.

No próximo capítulo é apresentada a heurística desenvolvida para ambas as abordagens: sem penalidade para antecipação de liga e com penalidade. 


\section{CAPÍtulo}

\section{4}

\section{Uma heurística para o problema}

\subsection{Considerações iniciais}

A heurística proposta neste capítulo é baseada na heurística lagrangiana apresentada em (TOLEDO, 1998), que considera a relaxação lagrangiana das restrições de capacidade do problema de dimensionamento de lotes em máquinas paralelas (PDLP). A heurística é composta de três fases: obtenção da solução inicial, factibilização e melhoria.

Nas próximas seções são descritas as heurísticas propostas para o problema de definição das ligas e para o problema de definição dos itens e são apresentados os testes realizados.

\subsection{Heurística para o Modelo das Ligas}

De acordo com testes realizados no capítulo anterior, foi adotado o Critério 5 para a definição de Kaux ligas no Modelo das Ligas, logo temos um novo número de ligas Kaux $(\operatorname{Kaux} \geq K)$.

A seguir é apresentada a descrição da heurística. 


\subsubsection{Relaxação lagrangiana}

Considere a relaxação lagrangiana em relação às restrições de capacidade (3.4) e sejam $\mu_{t l} \geq 0, t l=1, \ldots, T l$, os multiplicadores lagrangianos relacionados. O problema lagrangiano para o problema de decisão das ligas é dado por:

$\mathrm{g}\left(\mu_{t l}\right)=$ Minimizar

$$
\sum_{t l=1}^{T l} \sum_{\text {kaux }=1}^{\text {Kaux }}\left(H_{\text {kaux }, t l}^{-} E_{\text {kaux }, t l}^{-}+H_{\text {kaux }, t l}^{+} E_{\text {kaux }, t l}^{+}+s_{\text {kaux }} Y_{\text {kaux }, t l}\right)+\sum_{t l=1}^{T l} \mu_{t l}\left(\sum_{\text {kaux }=1}^{\text {Kaux }} A_{\text {kaux }, t l}-L\right)
$$

Sujeito a: $3.3,3.5,3.6,3.7$ e 3.8 .

Temos que $\mathrm{g}\left(\mu_{t l}\right)$ pode ser decomposto na soma da constante $-\sum_{t l=1}^{T l} \mu_{t l} L$ e $k a u x$ problemas independentes, um para cada liga, como apresentado a seguir:

$$
\begin{aligned}
& g_{\text {kaux }}\left(\mu_{t l}\right)=\text { Minimizar } \\
& \sum_{t l=1}^{T l}\left(H_{\text {kaux }, t l}^{-} E_{\text {kaux }, t l}^{-}+H_{\text {kaux }, t l}^{+} E_{\text {kaux }, t l}^{+}+s_{k a u x} Y_{k a u x, t l}+\mu_{t l} A_{k a u x, t l}\right)
\end{aligned}
$$

\section{Sujeito a}

$$
\begin{array}{ll}
E_{\text {kaux }, t l-1}^{+}-E_{\text {kaux }, t l-1}^{-}+C a p A_{\text {kaux }, t l}-E_{\text {kaux }, t l}^{+}+E_{\text {kaux }, t l}^{-}=D_{k a u x, t l} & t l=1, \ldots, T l \\
A_{\text {kaux }, t l} \leq L Y_{\text {kaux }, t l} & t l=1, \ldots, T l \\
Y_{\text {kaux }, t l} \in\{0,1\} & t l=1, \ldots, T l \\
A_{\text {kaux }, t l} \geq 0, \text { inteira } & t l=1, \ldots, T l \\
E_{\text {kaux }, t l}^{+} \text {e } E_{\text {kaux }, t l}^{-} \geq 0, E_{\text {kaux }, 0}^{+}=E_{\text {kaux }, 0}^{-}=0 & t l=1, \ldots, T l
\end{array}
$$

Cada um destes subproblemas é um problema de dimensionamento de lotes não capacitado, em que o atraso da demanda é permitido. Estes subproblemas podem ser resolvidos na otimalidade pelo algoritmo de programação dinâmica proposto por (ZANGWILL, 1969). Para esse algoritmo $C a p A_{k a u x, t l}$ é uma variável de decisão, como $D_{k a u x, t l}$ não é necessariamente múltiplo de Cap, $A_{k a u x, t l}$ pode ser real, logo é necessário arredondar para cima a solução do algoritmo antes de utilizá-la na heurística.

O método do subgradiente foi utilizado para maximizar a função dual $\mathrm{g}\left(\mu_{t l}\right)$ com $\mu_{t l} \geq 0, t l=1, \ldots, T l$. O tamanho do passo na direção do subgradiente é proporcional a 
um parâmetro $\lambda$ e a fórmula para gerar uma sequência decrescente para $\lambda$ é caracterizada pelos parâmetros $\left(\lambda_{0}, r_{0}, d, r_{m}\right)$, conforme descrito em (HELD et al., 1974; CROWDER, 1976). A sequência é inicializada fazendo $\lambda=\lambda_{0}$ para $r=r_{0}$ iterações. Após terminadas as $r$ iterações, tanto $\lambda$ quanto $r$ são divididos por $d$. Este processo é repetido até que $r \leq r_{m}$. O limitante superior utilizado no algoritmo do subgradiente é inicializado como infinito e então é atualizado de acordo com o valor da solução incumbente.

Testes computacionais mostraram que para o problema de definição das ligas, os melhores valores para os parâmetros $\left(\lambda_{0}, r_{0}, d, r_{m}\right)$ são $(1.75 ; 50 ; 2 ; 5)$ e o número máximo de iterações (max_it) é 150 .

\subsubsection{Heurística lagrangiana}

Dada uma solução não factível obtida pelo problema de minimização lagrangiano, a fase de factibilização transfere produção entre períodos na tentativa de encontrar uma solução factível para o problema com a capacidade aumentada de $20 \%$, de modo a distribuir o excesso de capacidade entre os períodos (TOLEDO; ARMENTANO, 2006). Se a solução resultante não é factível, é retomada a capacidade original e a fase de factibilização é aplicada novamente. Finalmente, a partir de uma solução factível, a fase de melhoria procura soluções com custos menores. A fase de factibilização é aplicada para o problema lagrangiano a cada passo $k$ do método do subgradiente. A heurística proposta é resumida no seguinte algoritmo:

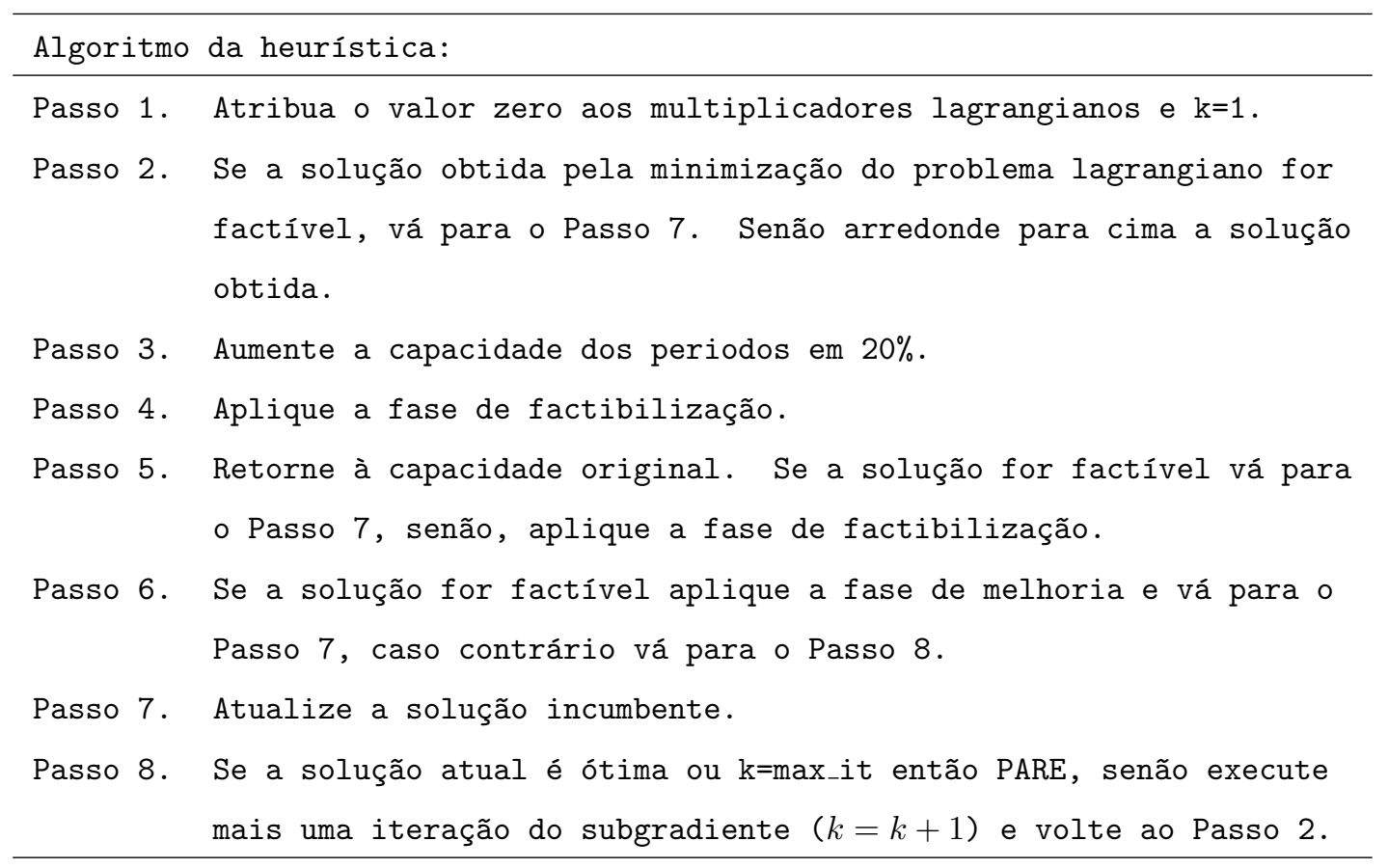


Como é permitido o atraso no atendimento da demanda e a produção total é superior à capacidade disponível total, para que esta heurística pudesse ser utilizada, foi necessário considerar um período a mais no problema, para que o mesmo não fosse considerado infactível. Chamamos este período de período fantasma, onde as penalidades foram calculadas como se houvesse um dia de programação a mais, sem demanda e com capacidade infinita. Sem perda de generalidade, podemos continuar considerando $t l=1, \ldots, T l$.

A seguir as fases de factibilização e de melhoria são descritas detalhadamente.

\section{Fase de factibilização}

Suponha que a solução inicial não seja factível com relação às restrições relaxadas, isto é, o número máximo de fornadas é excedido em um ou mais períodos. A partir desta solução, tenta-se construir uma solução factível através da transferência de quantidades de produção de períodos não factíveis para outros períodos.

Seja

$$
\Delta(t l)=\sum_{\text {kaux }=1}^{\text {Kaux }} A_{\text {kaux }, t l}-L .
$$

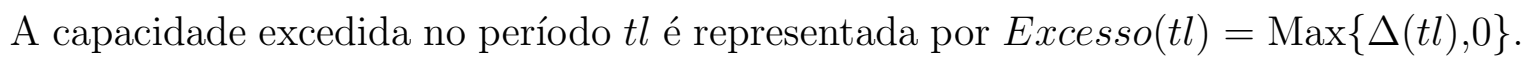

Para eliminar o Excesso( $(t)$, escolhemos uma quantidade $q$ da liga kaux produzida em $t l$ para transferir para $t d \operatorname{com} t d \neq t l$. A quantidade $q$ é definida como

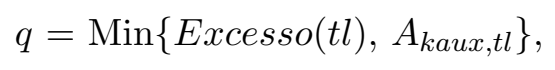

ou seja, é o menor valor entre o excesso no período e a quantidade máxima de liga kaux que pode ser transferida (toda a produção $A_{\text {kaux,tl}}$ ).

Após testes realizados, a definição do melhor critério para a seleção de $(q, k a u x, t d)$, que indica a quantidade $q$ da liga kaux para ser transferida para o período $t d$, foi definida como a que minimiza:

$$
\frac{\text { VariacaoCusto }+(\beta * \text { Penalidade })}{\text { ReducaoExcesso }}
$$

A variação de custo da transferência da quantidade $q$ da liga kaux do período $t l$ para o período $t d$ é dado por:

$$
\text { VariacaoCusto }=\frac{\left(\text { VariacaoFobj }+\left(1-Y_{\text {kaux }, t d}\right) s_{k a u x}-\sigma s_{k a u x}\right)}{\frac{F o b j}{T l * K}}
$$


em que VariacaoFobj é diferença do valor da função objetivo depois e antes da transferência e $\sigma=1$ se $q=A_{\text {kaux }, t l}$ e 0 caso contrário.

A penalidade representa um custo por excesso de capacidade em $t l$ e $t d$ e é dada por:

$$
\text { Penalidade }=\frac{(\text { ExcessoDepois }(t l)+(\text { ExcessoDepois }(t d)-\text { ExcessoAntes }(t d)))}{L}
$$

em que:

- ExcessoDepois $(t l)=\operatorname{Max}\{0, \Delta(t l)-q\}$

- ExcessoDepois $(t d)=\operatorname{Max}\{0, \Delta(t d)+q\}$

- ExcessoAntes $(t d)=\operatorname{Max}\{0, \Delta(t d)\}$

O fator $\beta$, definido como $15 \%$, representa um peso para a penalidade. E finalmente, a redução de excesso é representada por:

$$
\text { ReducaoExcesso }=\frac{q}{L}
$$

Esta fase consiste de um passo regressivo e um passo progressivo. No passo regressivo, as transferências de produção são analisadas do período fantasma para o segundo, portanto na seqüência $t l=T l, T l-1, \ldots, 2$. Para cada período $t l$ que exceda a capacidade $L$, transfere-se quantidades de ligas de $t l$ para $t d(t d<t l)$, minimizando o critério (4.1), até que $t l$ respeite a capacidade. Se após todas as transferências não houver excesso de capacidade no período 1, então uma solução factível para o problema foi obtida. Caso contrário, aplica-se o passo progressivo.

No passo progressivo, as transferências de produção são analisadas do período 1 para o período $T l-1$, ou seja, na ordem $t l=1,2, \ldots, T l-1$. Para cada período $t l$ que tenha a capacidade violada, transfere-se quantidades de ligas de $t l$ para $t d(t l<t d)$, minimizando o critério (4.1), até que $t l$ respeite a capacidade. Ao final deste passo é obtida uma solução factível para o problema, pois o período fantasma $T l$ tem capacidade infinita.

\section{Fase de melhoria}

A fase de melhoria parte de uma solução factível obtida no passo de factibilização e tenta reduzir o custo total da mesma. Para tal, esta fase tenta diminuir os estoques nos períodos, 
transferindo ligas entre os períodos, respeitando sempre a factibilidade da solução.

Esta fase é composta de um passo regressivo e progressivo. E é tratada de forma diferente dependendo se a penalidade para antecipação de liga é considerada ou não.

Seja Folga $(t d)=\operatorname{Max}\{-\Delta(t d), 0\}$.

Para a abordagem que não considera a penalidade, inicialmente no passo regressivo, um período com capacidade folgada é identificado examinando-se $t d=T l-1, \ldots, 1$. Então são considerados movimentos de produção de $t l=T l, \ldots, t d-1$ para $t d$ com capacidade folgada.

A quantidade de uma liga kaux produzida em $t l$ a ser transferida para $t d \operatorname{com} t l>t d$ é dada por:

$$
q=\operatorname{Min}\left\{F o l g a(t d), A_{k a u x, t l}\right\} .
$$

O primeiro termo representa a quantidade máxima da liga kaux que pode ser transferida para $t d$ sem violar a capacidade $L$, e o segundo resulta da produção $A_{k a u x, t l}$.

A seleção de $(q, k a u x, t l)$ é dada pelo primeiro valor que gera redução de custo. Se Folga $(t d)$ ainda é positiva depois da transferência, o processo é repetido na tentativa de reduzir o custo. O passo progressivo é similar.

Para a abordagem que considera a penalidade, inicialmente no passo regressivo, um período com capacidade folgada é identificado examinando-se $t d=T l-1, \ldots, 1$. Então são considerados movimentos de produção de $t l=T l, \ldots, t d-1$ para $t d$ com capacidade folgada.

A quantidade de uma liga kaux produzida em $t l$ a ser transferida para $t d \operatorname{com} t l>t d$ é $q=1$, pois testes preliminares mostraram que considerar $q$ da forma como foi calculado para a abordagem sem penalidade, não trouxe bons resultados. A seleção de $(k a u x, t l)$ é o que gera a melhor redução de custo enquanto há redução de custo. Se Folga(td) ainda é positiva depois da transferência, o processo é repetido na tentativa de reduzir ainda mais o custo. O passo progressivo é similar.

\subsection{Heurística para o Modelo das Peças}

Após obtida a solução do Modelo das Ligas, é feito um mapeamento das ligas kaux, kaux $=1, \ldots$, Kaux para cada liga original $k, k=1, \ldots, K$, e então são definidos os períodos onde há preparação para cada liga $k$, representado por $W_{k, t}, t=1, \ldots, T$. 
A seguir é apresentada a descrição da heurística.

\subsubsection{Relaxação lagrangiana}

Considere a relaxação lagrangiana em relação às restrições de capacidade (3.11) e sejam $\mu_{t} \geq 0, t=1, \ldots, T$, os multiplicadores lagrangianos relacionados. O problema lagrangiano para o problema de decisão das peças é dado por:

$$
\begin{aligned}
\mathrm{g}\left(\mu_{t}\right)= & \text { Minimizar } \\
& \sum_{t=1}^{T} \sum_{i \in S(k)}\left(H_{i, t}^{-} I_{i, t}^{-}+H_{i, t}^{+} I_{i, t}^{+}\right)+\sum_{t=1}^{T} \mu_{t}\left(\sum_{i \in S(k)} \rho_{i} X_{i, t}-C a p W_{k, t}\right)
\end{aligned}
$$

Sujeito a: $3.10,3.12$ e 3.13 .

Temos que $\mathrm{g}\left(\mu_{t}\right)$ pode ser decomposto na soma da constante $-\sum_{t=1}^{T} \mu_{t} C a p W_{k, t}$ e $i$ $(i \in S(k))$ problemas independentes, um para cada peça, como apresentado a seguir:

$$
\begin{aligned}
& g_{i}\left(\mu_{t}\right)=\text { Minimizar } \\
& \sum_{t=1}^{T}\left(H_{i, t}^{-} I_{i, t}^{-}+H_{i, t}^{+} I_{i, t}^{+}+\mu_{t} \rho_{i} X_{i, t}\right)
\end{aligned}
$$

\section{Sujeito a}

$$
\begin{array}{ll}
I_{i, t-1}^{+}-I_{i, t-1}^{-}+X_{i, t}-I_{i, t}^{+}+I_{i, t}^{-}=d_{i, t} & t=1, \ldots, T ; \\
X_{i, t} \geq 0, \text { inteira } & t=1, \ldots, T ; \\
I_{i, t}^{+} \text {e } I_{i, t}^{-} \geq 0, I_{i, 0}^{+}=I_{i, 0}^{-}=0 & t=1, \ldots, T .
\end{array}
$$

Estes problemas são resolvidos de forma similar aos subproblemas $g_{k a u x}\left(\mu_{t l}\right)$, exceto pelo fato de que não foram necessários arredondamentos e de que pode haver produção de itens $i(i \in S(k))$ somente nos períodos onde há preparação para a liga $k$, ou seja, as produções não são permitidas em todos os períodos $t, t=1, \ldots, T$. Para que isso fosse retratado, foi criado um custo de preparação para cada período $t$ com valor zero nos períodos onde há preparação para a liga e infinito nos períodos sem preparação.

Testes computacionais mostraram que para o problema de definição dos itens, os melhores valores para os parâmetros $\left(\lambda_{0}, r_{0}, d, r_{m}\right)$ do método do subgradiente são (1.75; $25 ; 2 ; 10)$ e o número máximo de iterações (max_it) é 50. 


\subsubsection{Heurística lagrangiana}

A proposta de resolução é baseada na anterior, com a exceção de que as transferências não podem ser para qualquer período, somente para os períodos onde houve preparação.

A seguir as fases de factbilização e de melhoria são descritas detalhadamente.

\section{Fase de factibilização}

Suponha que a solução inicial não seja factível com relação às restrições relaxadas, isto é, a capacidade do forno é excedida em um ou mais períodos. A partir desta solução, tenta-se construir uma solução factível através da transferência de quantidades de produção de períodos não factíveis para outros períodos.

Seja

$$
\Delta(t)=\sum_{i \in S(k)} \rho_{i} X_{i, t}-C a p W_{k, t}
$$

A capacidade excedida no período $t$ é representada por $\operatorname{Excesso}(t)=\operatorname{Max}\{\Delta(t), 0\}$.

Para eliminar o Excesso $(t)$, é escolhida uma quantidade $q$ do item $i$ produzido em $t$ para $t d$ com $t d \neq t$. A quantidade $q$ é definida como

$$
q=\operatorname{Min}\left\{\left\lceil\frac{\operatorname{Excesso}(t)}{\rho_{i}}\right\rceil, X_{i, t}\right\}
$$

ou seja, é o menor valor entre o número de itens em excesso no período e a quantidade máxima de item $i$ que pode ser transferida (toda a produção $X_{i, t}$ ). Esta fase consiste de um passo regressivo e um progressivo que são análogos aos descritos anteriormente. Destacam-se a seguir apenas as diferenças entre os dois.

No passo regressivo, $t=T, T-1, \ldots, s$, em que $s$ é o segundo período em que houve preparação para a liga $k$. Para cada período $t$ que exceda a capacidade $C a p$ e que tem preparação do forno para a liga $k$, transfere-se quantidades de itens produzidos em $t$ para $t d(t d<t)$ até que $t$ respeite a capacidade. O período $t d$ é o primeiro, anterior a $t$, em que $X_{i, t}$ é produzido.

No passo progressivo, $t=1,2, \ldots, p$, em que $p$ é o penúltimo período em que houve preparação para a liga $k$. Para cada período $t$ que tenha a capacidade violada e tem preparação do forno para a liga $k$, transfere-se quantidades de itens produzidos em $t$ para $t d(t<t d)$ até que $t$ respeite a capacidade. Após terminado este passo é obtida uma solução factível para o problema pois o período fantasma $T$ tem capacidade infinita. 


\section{Fase de melhoria}

Esta fase é análoga ao do Problema das Ligas, exceto pelo fato de que somente são analisados os períodos em que há preparação para determinada liga $k$ e a forma de calcular q, que é dada por:

$$
q=\operatorname{Min}\left\{\left\lfloor\frac{F o l g a(t d)}{\rho_{i}}\right\rfloor, X_{i, t}\right\}
$$

O primeiro termo representa a quantidade máxima do item $i$ que pode ser transferida para $t d$ sem violar a capacidade $C a p$, e o segundo resulta da produção $X_{i, t}$. A seleção de $(q, i, t)$ é o primeiro que gera redução de custo.

\subsection{Aprimoramento proposto}

A heurística para o problema conjunto (problema das ligas e $k$ problemas das peças) pode ser resumida no seguinte algoritmo:

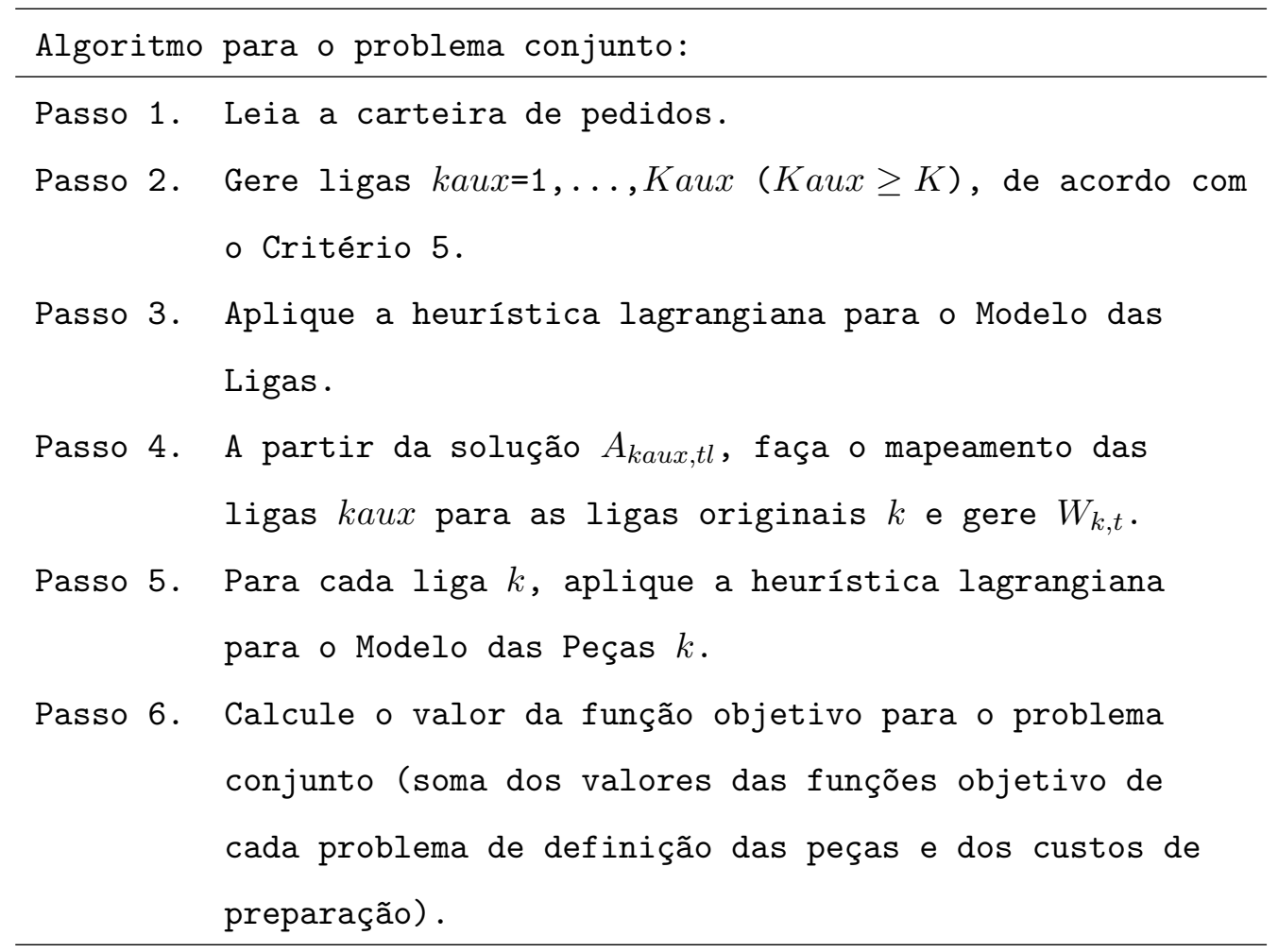


Um aprimoramento para a abordagem sem penalidade para antecipação de liga foi desenvolvido, e pode ser resumido no seguinte algoritmo:

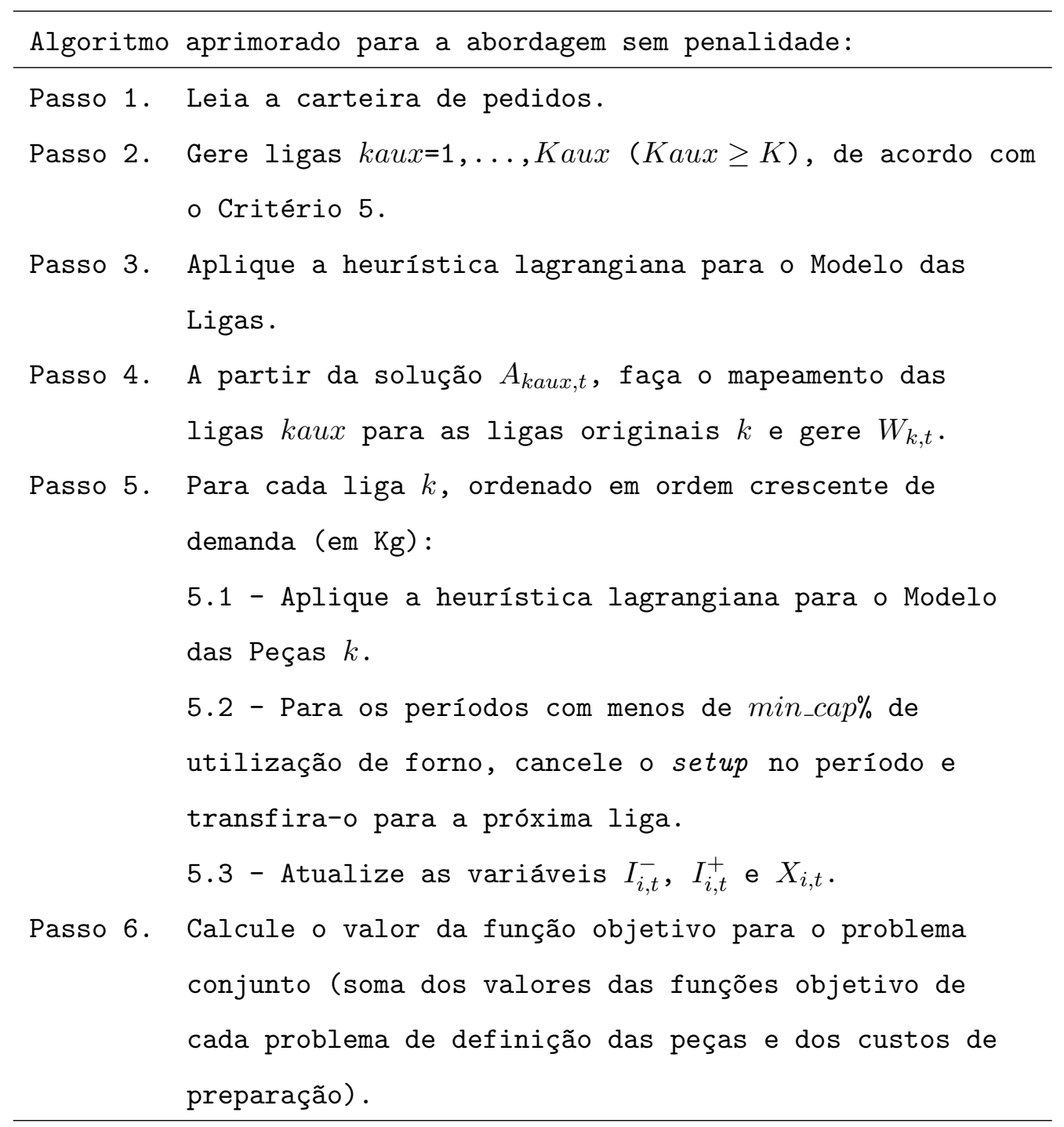

Com esta nova abordagem é possível controlar o grau de utilização do forno, e consequentemente o controle do "estoque" de liga, apenas modificando o parâmetro min_cap no Passo 5.2.

Para a abordagem com penalidade para antecipação de liga esse aprimoramento foi aplicado com min_cap $=120$, no entanto, os resultados não se alteraram, já que não haviam fornadas com menos de min_cap Kg fundidos. Por isso, foi proposto um aprimoramento baseado no número de fornadas ociosas, ou seja, a diferença entre o número máximo de fornadas permitidas no horizonte de planejamento e o número de fornadas para a qual houve preparação $\left(W_{k, t}=1\right)$. O aprimoramento é descrito no algoritmo a seguir. 


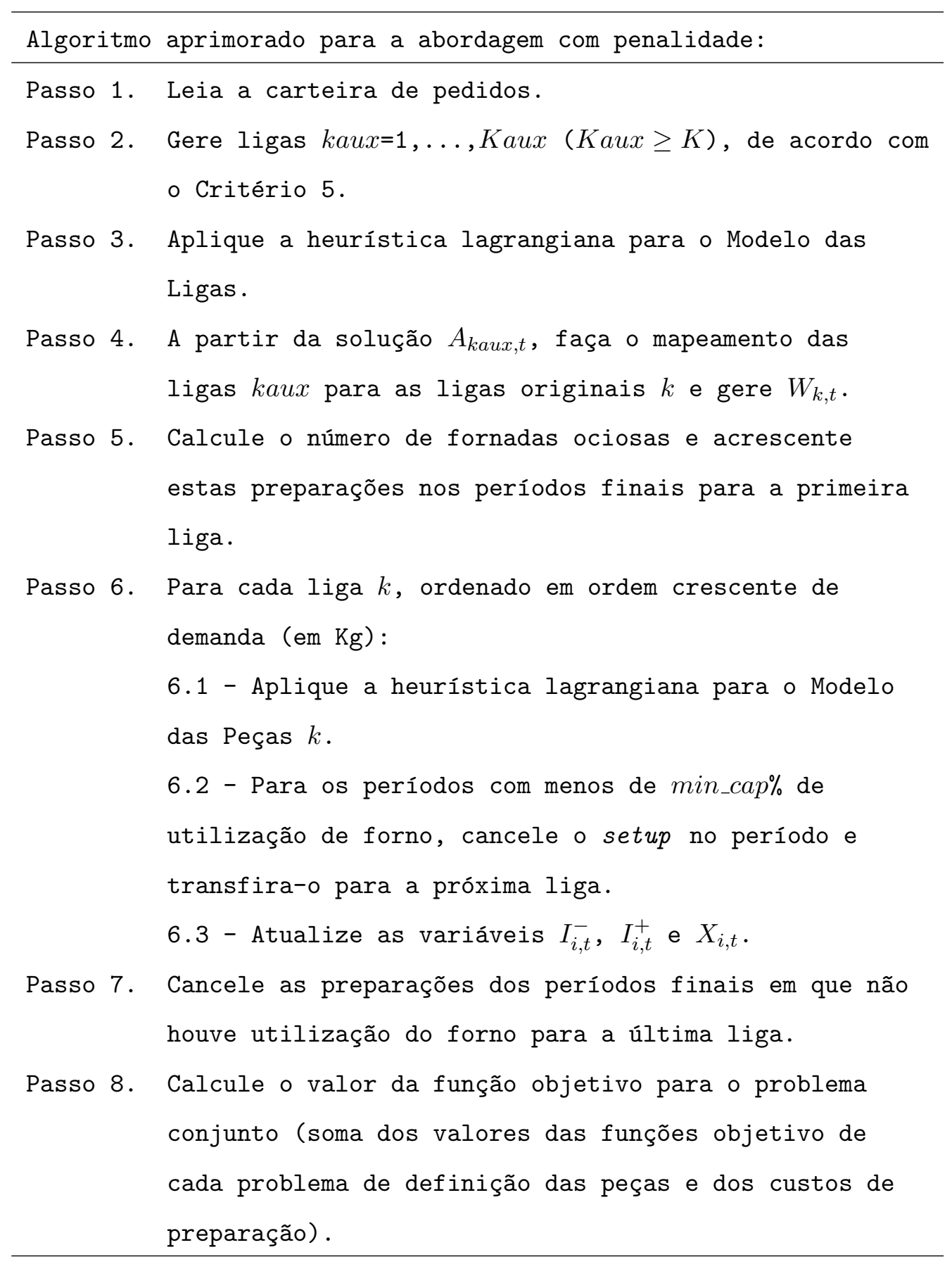

Testes computacionais para avaliar as heurísticas propostas são apresentados na próxima seção.

\subsection{Testes computacionais}

Para a realização dos testes foram considerados todos os cenários descritos no capítulo anterior e o Critério 5. Foi utilizado um computador Pentium 4, 2,8 GHz com $512 \mathrm{MB}$ de memória RAM. 
A heurística foi desenvolvida em linguagem $\mathrm{C}$ e necessita de dois arquivos de entrada e gera dois arquivos de saída, um para a programação das ligas e outro para a programação das peças. Exemplos desses arquivos são apresentados no Apêndice A.

Inicialmente, é apresentada uma análise da heurística para as abordagens sem e com penalidade para antecipação de liga. Em seguida, é avaliado o comportamento da heurística para o Modelo das Peças e então são analisados os resultados referentes ao aprimoramento proposto.

\subsubsection{Heurística de decomposição}

Em relação à abordagem sem penalidade para antecipação de liga, são analisadas a qualidade da solução, a utilização do forno e a fase de melhoria. Os resultados para a avaliação da qualidade da solução obtida pela heurística são apresentados na Tabela 4.1.

Tabela 4.1: Resultado da heurística para a abordagem sem penalidade.

\begin{tabular}{|c|c|c|c|c|}
\hline Cenário & $\mathrm{Fo}_{\mathrm{Hs}}$ & $T_{H s}(\mathrm{~s})$ & $\mathrm{GapFo}_{H s-C}(\%)$ & $\mathrm{GapFo}_{H s-D s}(\mathbf{\%})$ \\
\hline 1 & 202125,59 & 4,48 & 13,51 & 8,54 \\
\hline 2 & 210268,95 & 25,75 & 2,09 & 8,76 \\
\hline 3 & 224868,06 & 6,11 & 8,66 & 8,22 \\
\hline 4 & 262568,12 & 45,74 & $-12,44$ & 2,91 \\
\hline 5 & 370888,68 & 6,05 & $-11,55$ & 5,68 \\
\hline 6 & 433590,84 & 35,33 & $-16,42$ & 2,99 \\
\hline 7 & 345738,37 & 6,11 & $-0,12$ & 9,64 \\
\hline 8 & 358130,43 & 35,17 & $-28,74$ & 2,17 \\
\hline 9 & 297808,68 & 5,94 & 3,86 & 7,08 \\
\hline 10 & 319586,43 & 35,25 & $-16,01$ & 8,12 \\
\hline 11 & 545579,81 & 60,09 & $-12,77$ & 2,76 \\
\hline Média & & & $-6,36$ & 6,08 \\
\hline
\end{tabular}

A coluna $\mathrm{Fo}_{\mathrm{Hs}}$ indica o valor da função objetivo obtido pela heurística, $T_{H s}$ representa o tempo de execução em segundos, a coluna $\operatorname{GapF}_{\mathrm{Hs}_{s} \mathrm{C}}$ é calculada da forma:

$$
\frac{F o_{H s}-F o_{C}}{F o_{H s}} * 100
$$

e $G a p F o_{H s-D s}$ é:

$$
\frac{F o_{H s}-F o_{D s}}{F o_{H s}} * 100
$$


em que $F o_{C}$ é o valor da função objetivo para o Modelo Completo e $F o_{D s}$ é o valor da função objetivo para a abordagem de decomposição sem penalidade para antecipação de liga.

A heurística apresenta bons resultados em relação à abordagem de decomposição resolvida pelo CPLEX, que por sua vez está bem próximo da solução ótima (Cenário 5 da Tabela 3.5), além de apresentar, em média, um resultado melhor que o Modelo Completo resolvido pelo CPLEX. Além disso, o tempo de execução é bem menor: no máximo 60,09 segundos para a heurística comparados à 1 hora para o Modelo Completo e a abordagem de decomposição, ambos resolvidos pelo CPLEX.

Os resultados para a avaliação da utilização do forno pela heurística são apresentados na Tabela 4.2 .

Tabela 4.2: Utilização do forno pela heurística para a abordagem sem penalidade.

\begin{tabular}{|c|c|c|c|c|c|c|c|}
\hline Cenário & $N f_{H s}$ & $N f 360_{H s}$ & $N f 360 u_{H s}$ & $N f 120_{H s}$ & $S u b_{H s}$ & $\begin{array}{c}\text { GapSub } \\
(\mathbf{\%}-C\end{array}$ & $\begin{array}{c}\text { GapSub }{ }_{H s-D s} \\
(\mathbf{\%})\end{array}$ \\
\hline \hline 1 & 30 & 3 & 2 & 0 & 1490,50 & 73,21 & 51,53 \\
\hline 2 & 50 & 10 & 7 & 1 & 4136,10 & 52,22 & $-0,13$ \\
\hline 3 & 30 & 0 & 0 & 0 & 15,20 & $-492,76$ & $-313,82$ \\
\hline 4 & 50 & 2 & 2 & 0 & 855,85 & 88,69 & $-3,10$ \\
\hline 5 & 30 & 0 & 0 & 0 & 867,15 & $-30,87$ & 3,89 \\
\hline 6 & 50 & 2 & 1 & 1 & 2627,00 & $-72,15$ & 4,58 \\
\hline 7 & 30 & 0 & 0 & 1 & 1517,20 & 38,25 & 47,34 \\
\hline 8 & 50 & 3 & 2 & 1 & 2936,80 & $-19,94$ & $-7,48$ \\
\hline 9 & 30 & 0 & 0 & 0 & 867,15 & $-20,94$ & 3,89 \\
\hline 10 & 50 & 6 & 5 & 2 & 4268,70 & $-26,47$ & 0,00 \\
\hline 11 & 50 & 1 & 0 & 1 & 2040,80 & $-15,62$ & 24,42 \\
\hline Média & & & & 1965,68 & $-38,76$ & $-17,17$ \\
\hline
\end{tabular}

A coluna $N f_{H s}$ representa o número de preparações de fornos $\left(W_{k, t}=1\right), N f 360_{H s}$ indica o número de fornadas para a qual houve preparação, mas que não foram utilizadas, a coluna $N f 360 u_{H s}$ indica o número de fornadas que não foram utilizadas no último período, que na prática, poderiam deixar de ser feitas sem alteração no valor da função objetivo, $N f 120_{H s}$ indica o número de fornadas com utilização de menos de $33 \%$ do forno, a coluna $S u b_{H s}$ indica a quantidade (em $\mathrm{Kg}$ ) de forno não utilizado, considerando inclusive as fornadas para as quais houve preparação e não foram utilizadas e, por fim, a coluna 
$\operatorname{GapSub}_{H s-C}$ foi calculada da forma:

$$
\frac{S u b_{H s}-S u b_{C}}{S u b_{H s}} * 100
$$

e $G a p S u b_{H s-D s}$ é:

$$
\frac{S u b_{H s}-S u b_{D s}}{S u b_{H s}} * 100,
$$

em que $S u b_{C}$ é a subutilização em Kg para o Modelo Completo e $S u b_{D s}$ é a subutilização em Kg para a abordagem de decomposição sem penalidade para antecipação de liga.

Em relação à ocupação do forno há melhora tanto na comparação com o Modelo Completo quanto com a abordagem de decomposição, ambos resolvidos pelo CPLEX. Houve diminuição no número de fornadas com utilização de menos de $33 \%$ da capacidade do forno e grande parte dos fornos para os quais houve preparação sem utilização ficaram no último período.

Resultados com relação à fase de melhoria da heurística são apresentados na Tabela 4.3.

Tabela 4.3: Fase de melhoria da heurística para a abordagem sem penalidade.

\begin{tabular}{|c|c|c|c|c|}
\hline Cenário & MelL $L_{H s} \mathbf{( \% )}$ & TmelL $_{H s} \mathbf{( \% )}$ & MelP $_{H s} \mathbf{( \% )}$ & TmelP $_{H s}(\mathbf{\%})$ \\
\hline \hline 1 & 0,53 & 8,56 & 26,44 & 3,30 \\
\hline 2 & 0,36 & 0,00 & 31,86 & 1,48 \\
\hline 3 & 0,04 & 0,00 & 8,15 & 2,13 \\
\hline 4 & 0,15 & 0,00 & 11,33 & 0,69 \\
\hline 5 & 0,88 & 0,00 & 34,15 & 1,94 \\
\hline 6 & 0,58 & 0,00 & 38,43 & 0,51 \\
\hline 7 & 0,96 & 0,00 & 13,60 & 1,62 \\
\hline 8 & 0,21 & 0,00 & 16,73 & 0,64 \\
\hline 9 & 0,56 & 0,00 & 34,15 & 1,68 \\
\hline 10 & 0,00 & 0,00 & 39,62 & 0,92 \\
\hline 11 & 0,15 & 0,48 & 2,59 & 0,48 \\
\hline Média & 0,40 & 0,82 & 23,37 & 1,40 \\
\hline
\end{tabular}

A coluna $M e l L_{H s}$ representa a melhoria percentual da solução do problema das ligas na fase de melhoria e foi calculada da forma:

$$
\frac{\text { MedSolAntes }- \text { MedSolDepois }}{F_{L}} * 100,
$$

em que MedSolAntes é a média da solução do problema das ligas antes da fase de melhoria, MedSolDepois é a média da solução do problema das ligas depois da fase de melhoria, 
e $F o_{L}$ é o valor da função objetivo para o problema da liga.

A coluna $T$ mel $L_{H s}$ representa o tempo percentual de execução da fase de melhoria e é calculada da forma:

$$
\frac{T f m_{L}}{T_{L}} * 100
$$

em que $T f m_{L}$ é o tempo total da fase de melhoria e $T_{L}$ é tempo de execução do problema das ligas.

Como são executados vários problemas das peças, um para cada liga, foram calculadas as melhorias percentuais em relação a cada problema da peça com alguma preparação para a liga, pois quando não há preparação para a liga a solução é única, ou seja, todos os itens atrasam e a fase de melhoria não tem efeito. A média geral é representada pela coluna MelP $P_{\text {s }}$ :

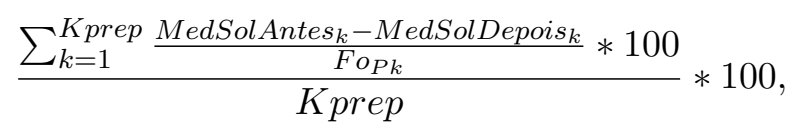

em que Kprep é o número de ligas para as quais houve preparação, MedSolAntes é a média da solução do problema da peça $k$ antes da fase de melhoria, MedSolDepois $s_{k}$ é a média da solução do problema da peça $k$ depois da fase de melhoria, e $F o_{P k}$ é o valor da função objetivo para o problema da peça $k$.

A coluna $T$ mel $P_{H s}$ representa o tempo percentual de execução da fase de melhoria e é calculada da forma:

$$
\frac{T f m_{P}}{T_{P}} * 100
$$

em que $T \mathrm{fm}_{P}$ é o tempo total da fase de melhoria do problema das peças e $T_{L}$ é tempo total de execução do problema das peças.

Para o problema das ligas, a fase de melhoria melhorou muito pouco a solução obtida pela fase de factibilização e o tempo gasto no processamento foi muito baixo. Isto indica que pode haver um investimento no aprimoramento desta fase.

Para o problema das peças, a fase de melhoria trabalhou bem, em alguns cenários é responsável pela melhora de $39 \%$ no valor da função objetivo, dando indícios de que a fase de melhoria está funcionando bem. Testes para avaliar a qualidade da solução do problema das peças são apresentados na próxima seção.

Agora são apresentados os resultados com relação à abordagem com penalidade para antecipação de liga. A avaliação da qualidade da solução obtida pela heurística é apresentada na Tabela 4.4. 
Tabela 4.4: Resultado da heurística para a abordagem com penalidade.

\begin{tabular}{|c|c|c|c|c|}
\hline Cenário & $F_{H c}$ & $T_{H c}(\mathbf{s})$ & $G a p F_{H c-C}(\mathbf{\%})$ & $G a p F_{H c-D c} \mathbf{( \% )}$ \\
\hline \hline 1 & 185511,86 & 4,47 & 5,76 & 6,50 \\
\hline 2 & 245265,81 & 25,59 & 16,06 & 11,37 \\
\hline 3 & 216612,41 & 6,16 & 5,18 & 7,79 \\
\hline 4 & 255778,27 & 46,09 & $-15,42$ & 2,85 \\
\hline 5 & 380818,97 & 6,11 & $-8,64$ & 4,26 \\
\hline 6 & 519802,94 & 36,33 & 2,89 & 1,92 \\
\hline 7 & 341375,59 & 6,26 & $-1,40$ & 2,40 \\
\hline 8 & 486959,94 & 34,89 & 5,32 & 1,70 \\
\hline 9 & 300473,31 & 6,12 & 4,71 & 0,78 \\
\hline 10 & 450368,38 & 34,92 & 17,68 & 2,65 \\
\hline 11 & 593899,38 & 60,17 & $-3,59$ & 3,01 \\
\hline Média & \multicolumn{2}{r|}{} & 2,59 & 4,11 \\
\hline
\end{tabular}

A coluna $F o_{H c}$ indica o valor da função objetivo para a heurística, $T_{H c}$ representa o tempo de execução em segundos, e as colunas $G a p F o_{H c-C}$ e $G a p F o_{H c-D c}$ foram calculadas de forma equivalente aos gaps da Tabela 4.1 levando em consideração as abordagens com penalidade para antecipação de liga.

A heurística apresenta bons resultados em relação à abordagem de decomposição resolvida pelo CPLEX, que por sua vez está perto da solução ótima (Cenário 5 da Tabela 3.9). Além disso, em alguns cenários foram obtidos resultados melhores que o Modelo Completo resolvido pelo CPLEX. O tempo de execução continua bem menor: no máximo 60,17 segundos comparados à 1 hora.

Os resultados para a avaliação da utilização do forno pela heurística são apresentados na Tabela 4.5. As colunas têm o mesmo significado das colunas da Tabela 4.2, porém, agora é considerada a abordagem com penalidade para antecipação de liga. 
Tabela 4.5: Utilização do forno pela heurística para a abordagem com penalidade.

\begin{tabular}{|c|c|c|c|c|c|c|c|}
\hline Cenário & $N f_{H c}$ & $N f 360_{H c}$ & $N f 360 u_{H c}$ & $N f 120_{H c}$ & $S u b_{H c}$ & $\begin{array}{c}\text { GapSub } \\
\mathbf{H c - C}\end{array}$ & $\begin{array}{c}\text { GapSub } \\
\mathbf{( \% )} \mathbf{)}\end{array}$ \\
\hline \hline 1 & 30 & 0 & 0 & 0 & 137,10 & $-191,25$ & 26,44 \\
\hline 2 & 33 & 0 & 0 & 0 & 140,35 & $-1307,98$ & 1,35 \\
\hline 3 & 30 & 0 & 0 & 0 & 115,40 & 21,92 & 24,44 \\
\hline 4 & 50 & 0 & 0 & 0 & 120,70 & 19,80 & 0,37 \\
\hline 5 & 30 & 0 & 0 & 0 & 145,35 & $-680,74$ & 9,74 \\
\hline 6 & 36 & 0 & 0 & 0 & 172,95 & $-2514,80$ & 6,71 \\
\hline 7 & 30 & 0 & 0 & 0 & 101,80 & $-820,33$ & 13,16 \\
\hline 8 & 31 & 0 & 0 & 0 & 104,00 & $-3286,88$ & 12,12 \\
\hline 9 & 27 & 0 & 0 & 0 & 63,55 & $-1550,28$ & 25,41 \\
\hline 10 & 27 & 0 & 0 & 0 & 63,55 & $-8395,36$ & 16,05 \\
\hline 11 & 50 & 0 & 0 & 0 & 134,60 & $-1653,01$ & 13,78 \\
\hline Média & & & & & 118,12 & $-1850,81$ & 13,60 \\
\hline
\end{tabular}

Para a abordagem de decomposição resolvida pelo CPLEX a subutilização média foi de 103,26 Kg, portanto, temos uma subutilização do forno um pouco maior, porém, não muito significativo. Em relação ao Modelo Completo resolvido pelo CPLEX, a quantidade de forno subutilizado é muito menor.

Resultados com relação à fase de melhoria da heurística são apresentados na Tabela 4.6. As colunas $M e l L_{H c}$, Tmel $L_{H c}, M e l P_{H c}$, e Tmel $P_{H c}$ foram calculadas da mesma forma que as colunas da Tabela 4.3. 
Tabela 4.6: Fase de melhoria da heurística para a abordagem com penalidade.

\begin{tabular}{|c|c|c|c|c|}
\hline Cenário & MelL $L_{\mathrm{Hc}} \mathbf{( \% )}$ & Tmel $_{\mathrm{Hc}} \mathbf{( \% )}$ & MelP $_{\mathrm{Hc}} \mathbf{( \% )}$ & TmelP $_{H c} \mathbf{( \% )}$ \\
\hline \hline 1 & 1460213,55 & 57,75 & 33,37 & 2,90 \\
\hline 2 & 1740273,40 & 63,27 & 43,40 & 0,31 \\
\hline 3 & 1481143,47 & 36,70 & 11,92 & 1,60 \\
\hline 4 & 1855503,11 & 56,40 & 15,51 & 0,79 \\
\hline 5 & 949219,05 & 37,33 & 10,89 & 3,82 \\
\hline 6 & 1182472,17 & 38,27 & 22,56 & 0,68 \\
\hline 7 & 791794,26 & 37,87 & 14,85 & 2,67 \\
\hline 8 & 1126950,57 & 52,09 & 26,65 & 0,50 \\
\hline 9 & 953467,96 & 26,85 & 14,06 & 2,22 \\
\hline 10 & 1374228,41 & 50,17 & 20,45 & 0,55 \\
\hline 11 & 1096966,99 & 49,13 & 9,15 & 0,45 \\
\hline Média & 1273839,36 & 45,98 & 20,26 & 1,50 \\
\hline
\end{tabular}

Para o problema das ligas, a fase de melhoria melhorou muito a solução obtida pela fase de factibilização e foi gasto boa parte do processamento do problema nesta fase. Isto demonstra que pode ser feito um investimento no aprimoramento da fase de factibilização.

Para o problema das peças, houve melhora razoável da solução em pouco tempo. A análise da heurística para o Modelo das Peças é apresentado na seção seguinte.

\subsubsection{Heurística para o Modelo das Peças}

Para que fosse avaliada a qualidade da solução da heurística para o Modelo das Peças, foram realizados testes com a solução ótima obtida pelo CPLEX para o Modelo das Ligas. Os resultados para a abordagem sem e com penalidade para a antecipação de liga, são apresentados na Tabela 4.7 . 
Tabela 4.7: Avaliação do Modelo das Peças.

\begin{tabular}{|c|c|c|c|c|}
\hline Cenário & $F_{o O t} t_{H}$ & GapFoOt $_{H s-D s}(\mathbf{\%})$ & $F_{o O t}{ }_{H c}$ & GapFoOt $_{H c-D c}(\mathbf{\%})$ \\
\hline \hline 1 & 185164,61 & 0,17 & 176090,06 & 1,49 \\
\hline 2 & 192694,66 & 0,44 & 221257,50 & 1,76 \\
\hline 3 & 209842,00 & 1,65 & 204665,12 & 2,41 \\
\hline 4 & 256788,67 & 0,72 & 251783,27 & 1,30 \\
\hline 5 & 354439,53 & 1,31 & 366734,81 & 0,58 \\
\hline 6 & 425318,09 & 1,10 & 514487,22 & 0,91 \\
\hline 7 & 317051,16 & 1,46 & 336114,28 & 0,87 \\
\hline 8 & 355184,53 & 1,36 & 483328,84 & 0,96 \\
\hline 9 & 281359,53 & 1,65 & 300152,91 & 0,67 \\
\hline 10 & 297855,03 & 1,42 & 443127,22 & 1,05 \\
\hline 11 & 537332,94 & 1,26 & 582578,69 & 1,13 \\
\hline Média & & 1,14 & & 1,19 \\
\hline
\end{tabular}

A coluna $\mathrm{FoOt}_{H s}$ representa o valor da função objetivo da heurística sem penalidade para antecipação da liga, $F o O t_{H c}$ representa o valor da função objetivo da heurística com penalidade para antecipação da liga e a coluna $\mathrm{GapFoOt}_{H s-D s}$ é calculada da forma:

$$
\frac{F_{o O t_{H s}}-F_{o_{D s}}}{F_{o O t_{H s}}} * 100
$$

e GapFoOt $t_{H c-D c}$ é:

$$
\frac{F_{o O t_{H c}}-F o_{D c}}{F o O t_{H c}} * 100
$$

É possível concluir que tanto para a abordagem sem penalidade para antecipação da liga, quanto para a abordagem com penalidade, a heurística para o Modelo das Peças é muito eficiente, ficando a aproximadamente 1,5\% da solução da abordagem de decomposição obtida pelo CPLEX.

Esse fato nos levou a considerar a possibilidade da heurística alterar algumas preparações na busca de melhores soluções. O aprimoramento sugerido é discutido na seção seguinte.

\subsubsection{Aprimoramento proposto para a heurística}

Para o aprimoramento proposto, tanto em relação à abordagem que não considera penalidade para antecipação de liga, quanto para a abordagem que considera, min_cap foi definido como $120 \mathrm{Kg}$. 
Primeiramente é apresentada a abordagem sem penalidade para antecipação de liga. A análise da qualidade da solução para a heurística (Algoritmo aprimorado para a abordagem sem penalidade) é apresentada na Tabela 4.8 .

Tabela 4.8: Resultados da heurística aprimorada para abordagem sem penalidade.

\begin{tabular}{|c|c|c|c|c|c|}
\hline Cenário & $\mathrm{Fo}_{H A s}$ & $T_{H A s}(\mathbf{s})$ & $\mathrm{GapFo}_{H A s-C}(\boldsymbol{\%})$ & $\mathrm{GapFo}_{H A s-D s}(\mathbf{\%})$ & $\mathrm{GapFo}_{H A s-H s}$ (\%) \\
\hline 1 & 196747,61 & 4,44 & 11,14 & 6,04 & $-2,73$ \\
\hline 2 & 200079,36 & 25,88 & $-2,90$ & 4,12 & $-5,09$ \\
\hline 3 & 224868,08 & 6,11 & 8,66 & 8,22 & 0,00 \\
\hline 4 & 260531,56 & 45,72 & $-13,31$ & 2,15 & $-0,78$ \\
\hline 5 & 370888,69 & 6,06 & $-11,55$ & 5,68 & 0,00 \\
\hline 6 & 423009,09 & 35,24 & $-19,33$ & 0,56 & $-2,50$ \\
\hline 7 & 337705,34 & 6,51 & $-2,50$ & 7,49 & $-2,38$ \\
\hline 8 & 343584,88 & 35,16 & $-34,19$ & $-1,97$ & $-4,23$ \\
\hline 9 & 297808,69 & 5,92 & 3,86 & 7,08 & 0,00 \\
\hline 10 & 318432,47 & 35,38 & $-16,43$ & 7,79 & $-0,36$ \\
\hline 11 & 541116,38 & 59,92 & $-13,70$ & 1,95 & $-0,82$ \\
\hline Média & & & $-8,20$ & 4,47 & $-1,72$ \\
\hline
\end{tabular}

A coluna $F o_{H A s}$ indica o valor da função objetivo obtido para heurística aprimorada, $T_{H A s}$ representa o tempo de execução em segundos, a coluna $G a p F_{H A s-C}$ é dada por:

$$
G a p o_{H A s-C}=\frac{F o_{H A s}-F o_{C}}{F o_{H A s}} * 100,
$$

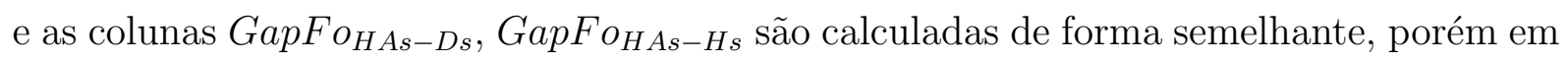
relação à decomposição e à heurística, respectivamente, abordagem sem penalidade para antecipação de liga.

Pode-se observar que em relação à heurística sem o aprimoramento há uma melhora média de $1,72 \%$ e, consequentemente, gaps menores em relação ao problema completo e à abordagem de decomposição resolvidos pelo CPLEX.

Além disso, é possível controlar o mínimo de liga a ser fundida em cada fornada, evitando assim a subutilização do forno. Porém, quanto maior a exigência de preenchimento do forno, pior o valor da solução do problema devido ao elevado número de peças em atraso no final da programação.

Os resultados para a avaliação da utilização do forno pela heurística são apresentados na Tabela 4.9 . 
Tabela 4.9: Utilização do forno pela heurística aprimorada para a abordagem sem penalidade.

\begin{tabular}{|c|c|c|c|c|c|c|c|c|}
\hline Cenário & $N f_{H A s}$ & $N f 360_{H A s}$ & $N f 360 u_{H A s}$ & $N f 120_{H A s}$ & $S_{H A s}$ & GapSub $_{H A s-C} \mathbf{( \% )}$ & GapSub $_{H A s-D s} \mathbf{( \% )}$ & GapSub $_{H A s-H s}(\mathbf{\%})$ \\
\hline \hline 1 & 30 & 2 & 2 & 0 & 1131,30 & 64,70 & 36,14 & $-31,75$ \\
\hline 2 & 50 & 11 & 9 & 0 & 4214,50 & 53,11 & 1,74 & 1,86 \\
\hline 3 & 30 & 0 & 0 & 0 & 15,20 & $-492,76$ & $-313,82$ & 0,00 \\
\hline 4 & 50 & 0 & 0 & 0 & 155,25 & 37,65 & $-468,37$ & $-451,27$ \\
\hline 5 & 30 & 0 & 0 & 0 & 867,15 & $-30,87$ & 3,89 & 0,00 \\
\hline 6 & 50 & 1 & 1 & 0 & 1987,00 & $-127,59$ & $-26,15$ & $-32,21$ \\
\hline 7 & 30 & 0 & 0 & 0 & 1221,00 & 23,27 & 34,56 & $-24,26$ \\
\hline 8 & 50 & 3 & 3 & 0 & 2768,60 & $-27,22$ & $-14,01$ & $-6,08$ \\
\hline 9 & 30 & 0 & 0 & 0 & 867,15 & $-20,94$ & 3,89 & 0,00 \\
\hline 10 & 50 & 8 & 8 & 0 & 4415,00 & $-22,28$ & 3,31 & 3,31 \\
\hline 11 & 50 & 0 & 0 & 0 & 1484,70 & $-58,92$ & $-3,89$ & $-37,46$ \\
\hline Média & & & & 1738,80 & $-54,71$ & $-67,52$ & $-52,53$ \\
\hline
\end{tabular}


As colunas $N f_{H A s}, N f 360_{H A s}, N f 360 u_{H A s}, N f 120_{H A s}$ e $S u b_{H A s}$ têm significado semelhante às da Tabela 4.2, agora, em relação ao aprimoramento, e os gaps foram calculados como os da Tabela 4.8, no entanto, considera-se a subutilização dos fornos.

Podemos verificar que além de melhorar a qualidade da solução, as fornadas foram melhor aproveitadas. Não houve fornadas com menos de $33 \%$ de utilização e além disso, a maioria dos fornos para os quais houve preparação e não foram utilizados, ficaram no último período. Como já foi destacado, ao aplicar o mesmo algoritmo para a abordagem que considera a penalidade para antecipação de liga, não houve nenhuma mudança. Dessa forma, nesta seção são apresentados os testes realizados para o aprimoramento proposto especialmente para o problema com penalidade por antecipação. Primeiramente é apresentada a avaliação da qualidade da solução obtida pela heurística na Tabela 4.10.

Tabela 4.10: Resultados da heurística aprimorada para abordagem com penalidade.

\begin{tabular}{|c|c|c|c|c|c|}
\hline Cenário & $F o_{H A c}$ & $T_{H A c}(\mathbf{s})$ & ${G a p F o_{H A c-C}}_{(\%)}$ & $G a p F_{H A c-D c} \mathbf{( \% )}$ & $G a p F o_{H A c-H c} \mathbf{( \% )}$ \\
\hline \hline 1 & 185511,86 & 4,41 & 5,76 & 6,50 & 0,00 \\
\hline 2 & 201459,56 & 26,22 & $-2,20$ & $-7,90$ & $-21,74$ \\
\hline 3 & 216612,39 & 6,11 & 5,18 & 7,79 & 0,00 \\
\hline 4 & 255778,27 & 46,00 & $-15,42$ & 2,85 & 0,00 \\
\hline 5 & 380819,00 & 6,01 & $-8,64$ & 4,26 & 0,00 \\
\hline 6 & 433300,44 & 35,05 & $-16,49$ & $-17,66$ & $-19,96$ \\
\hline 7 & 341375,56 & 6,05 & $-1,40$ & 2,40 & 0,00 \\
\hline 8 & 369937,56 & 35,13 & $-24,63$ & $-29,40$ & $-31,63$ \\
\hline 9 & 287441,41 & 6,05 & 0,39 & $-3,72$ & $-4,53$ \\
\hline 10 & 305838,44 & 35,48 & $-21,23$ & $-43,36$ & $-47,26$ \\
\hline 11 & 593899,38 & 60,20 & $-3,59$ & 3,01 & 0,00 \\
\hline Média & & & $-7,48$ & $-6,84$ & $-11,38$ \\
\hline
\end{tabular}

A coluna $F_{O_{H A c}}$ indica o valor da função objetivo, $T_{H A c}$ representa o tempo de execução em segundos, e os gaps foram calculados de forma similar aos da Tabela 4.8, porém, são consideradas as abordagens com penalidade para antecipação de liga.

Conclui-se que para os cenários onde houve fornadas ociosas, ou seja, os Cenários 2, 6, 8, 9 e 10, o valor da função objetivo melhorou significativamente. Em média, foram obtidos resultados melhores que todas as abordagens descritas anteriormente.

Os resultados para a avaliação da utilização do forno pela heurística são apresentados na Tabela 4.11 . 
Tabela 4.11: Utilização do forno pela heurística aprimorada para a abordagem com penalidade.

\begin{tabular}{|c|c|c|c|c|c|c|c|c|}
\hline Cenário & $N f_{H A c}$ & $N f 360_{H A c}$ & $N f 360 u_{H A c}$ & $N f 120_{H A c}$ & $S u b_{H A c}$ & $\operatorname{GapSub}_{H A c-C}(\%)$ & $\operatorname{GapSub}_{H A c-D c}(\boldsymbol{\%})$ & $\operatorname{GapSub}_{H A c-H c}(\boldsymbol{\%})$ \\
\hline 1 & 30 & 0 & 0 & 0 & 137,10 & $-191,25$ & 26,44 & 0,00 \\
\hline 2 & 39 & 0 & 0 & 0 & 254,50 & $-676,46$ & 45,60 & 44,85 \\
\hline 3 & 30 & 0 & 0 & 0 & 115,40 & 21,92 & 24,44 & 0,00 \\
\hline 4 & 50 & 0 & 0 & 0 & 120,70 & 19,80 & 0,37 & 0,00 \\
\hline 5 & 30 & 0 & 0 & 0 & 145,35 & $-680,74$ & 9,74 & 0,00 \\
\hline 6 & 50 & 0 & 0 & 0 & 1599,50 & $-182,73$ & 89,91 & 89,19 \\
\hline 7 & 30 & 0 & 0 & 0 & 101,80 & $-820,33$ & 13,16 & 0,00 \\
\hline 8 & 47 & 0 & 0 & 0 & 1688,60 & $-108,60$ & 94,59 & 93,84 \\
\hline 9 & 30 & 0 & 0 & 0 & 655,45 & $-60,00$ & 92,77 & 90,30 \\
\hline 10 & 42 & 0 & 0 & 0 & 1535,00 & $-251,71$ & 96,52 & 95,86 \\
\hline 11 & 50 & 0 & 0 & 0 & 134,60 & $-1653,01$ & 13,78 & 0,00 \\
\hline Média & & & & & 589,82 & $-416,65$ & 46,12 & 37,64 \\
\hline
\end{tabular}


Todas as colunas têm significado semelhante às da Tabela 4.9, porém, são consideradas as abordagens com penalidade para antecipação de liga.

Como já era esperado, com a melhoria obtida no valor da função objetivo pelo aprimoramento proposto, a quantidade de forno subutilizado aumentou. No entanto, em relação ao Modelo Completo resolvido pelo CPLEX, a subutilização do forno continua muito menor e além disso, considerando a heurística aprimorada para a abordagem sem penalidade para antecipação de liga, ao serem retiradas do cálculo da subutilização todas as fornadas para as quais houve preparação e não foram utilizadas, esta abordagem, ainda assim, subutiliza menos o forno.

\subsection{Considerações finais}

Inicialmente foi apresentado o desenvolvimento da heurística para o Modelos das Ligas e para o Modelo das Peças e então foram propostos aprimoramentos.

Foram realizados testes baseados nos 11 cenários descritos no capítulo anterior e para o agrupamento das ligas no Modelos das Ligas, foi utilizado o Critério 5.

Para a heurística proposta sem aprimoramento e considerando primeiramente a abordagem sem penalidade para antecipação de liga, foram obtidas soluções de boa qualidade e quantidade de forno subutilizado menor que a abordagem de decomposição resolvida pelo CPLEX. Porém, como este valor continua elevado, foi testada a abordagem com penalidade para antecipação de liga. As soluções obtidas foram, em média, um pouco piores que o Modelo Completo resolvido pelo CPLEX, porém, a quantidade de forno subutilizado caiu consideravelmente.

Em relação ao aprimoramento da heurística, a abordagem sem penalidade para antecipação de liga obteve resultados melhores tanto em relação à função objetivo quanto em relação à utilização do forno, porém a quantidade de forno subutilizado continuou alta. Foi testada a abordagem com penalidade, cuja qualidade da solução é, em média, 7,48\% melhor que o Modelo Completo resolvido pelo CPLEX, contra 8,2\% relacionado à abordagem sem penalidade, ou seja, é uma diferença pequena e, no entanto, a quantidade de forno subutilizado em relação ao Modelo Completo foi reduzida.

Pode-se observar que minimizar atrasos e aproveitar melhor o forno são objetivos conflitantes, ou seja, quanto melhor o aproveitamento do forno, maior o número de peças 
atrasadas no final do planejamento, já que são escolhidas para produção as peças que ocupam melhor o forno, e não necessariamente as mais atrasadas. No entanto, a heurística com o aprimoramento proposto para a abordagem com penalidade para antecipação de liga conseguiu obter uma boa solução em relação aos dois objetivos.

No próximo capítulo é feito um estudo de caso baseado em dados reais e são utilizadas para comparação as heurísticas com os aprimoramentos propostos, levando em consideração tanto à abordagem sem penalidade para antecipação de liga quanto a abordagem com penalidade. 


\section{Estudo de caso}

\subsection{Considerações iniciais}

Para avaliar a qualidade da heurística proposta neste trabalho em um caso real, foi feito um estudo de caso com dados de uma carteira de uma fundição de mercado de pequeno porte da cidade de São Carlos, cujo processo produtivo foi descrito no Capítulo 2.

O estudo de caso apresentado neste capítulo é representado pelo Cenário 11, ou seja, é utilizado um horizonte de planejamento de 5 dias com 10 fornadas ao dia, totalizando 50 fornadas no horizonte de planejamento. A capacidade do forno é $360 \mathrm{Kg}$ e a carteira de pedidos contém 383 itens produzidos a partir 19 ligas diferentes. Uma característica da carteira é que os pesos unitários dos itens têm grande variação $(0,5 \mathrm{Kg}$ a $200 \mathrm{Kg})$, assim como a quantidade demandada (1 a 1.000 itens).

Os resultados obtidos pela heurística aprimorada para a abordagem sem penalidade para antecipação de liga $\left(H A_{s}\right)$ e para a abordagem com penalidade $\left(H A_{c}\right)$, são comparados com os resultados obtidos em (ARAUJO et al., 2006a) para o método DH, que apresenta a melhor solução obtida para o problema até o momento presente, e também com o resultado obtido na prática. 


\subsection{Comparação dos resultados}

Inicialmente é feita a comparação do número de itens e da quantidade (em Kg) em estoque e em atraso entre os dias de programação. No início do período existiam 7.708 itens atrasados, totalizando $17.321,89 \mathrm{Kg}$, e não existiam itens estocados. Os resultados são apresentados nas Tabelas 5.1 e 5.2 .

Tabela 5.1: Atrasos e estoques em itens.

\begin{tabular}{|c|c|c|c|c|c|c|c|c|}
\cline { 2 - 9 } \multicolumn{1}{c|}{} & \multicolumn{2}{c|}{ DH } & \multicolumn{2}{c|}{ Prática } & \multicolumn{2}{c|}{$H A_{s}$} & \multicolumn{2}{c|}{$H A_{c}$} \\
\cline { 2 - 9 } \multicolumn{1}{c|}{} & Atrasos & Estoques & Atrasos & Estoques & Atrasos & Estoques & Atrasos & Estoques \\
\hline Dia 1 & 3705 & 0 & 3780 & 23 & 3616 & 33 & 3766 & 13 \\
\hline Dia 2 & 3393 & 0 & 3438 & 23 & 2787 & 51 & 2503 & 23 \\
\hline Dia 3 & 3171 & 0 & 3002 & 1 & 2741 & 21 & 1955 & 12 \\
\hline Dia 4 & 1265 & 22 & 2870 & 1 & 2396 & 47 & 1747 & 22 \\
\hline Dia 5 & 980 & 0 & 2566 & 1 & 2210 & 0 & 1346 & 0 \\
\hline Total & 12514 & 22 & 15656 & 49 & 13750 & 152 & 11317 & 70 \\
\hline
\end{tabular}

Tabela 5.2: Atrasos e estoques em Kg.

\begin{tabular}{|c|c|c|c|c|c|c|c|c|}
\cline { 2 - 9 } \multicolumn{1}{c|}{} & \multicolumn{2}{c|}{ DH } & \multicolumn{2}{c|}{ Prática } & \multicolumn{2}{c|}{$H A_{s}$} & \multicolumn{2}{c|}{$H A_{c}$} \\
\cline { 2 - 9 } \multicolumn{1}{c|}{} & Atrasos & Estoques & Atrasos & Estoques & Atrasos & Estoques & Atrasos & Estoques \\
\hline Dia 1 & 18101,90 & 0,00 & 18392,10 & 23,00 & 18142,75 & 31,20 & 18136,05 & 33,89 \\
\hline Dia 2 & 16615,50 & 0,00 & 16644,25 & 23,00 & 16557,05 & 103,00 & 16366,55 & 53,79 \\
\hline Dia 3 & 15014,95 & 0,00 & 14719,65 & 70,15 & 15319,70 & 85,00 & 14484,95 & 93,50 \\
\hline Dia 4 & 13720,30 & 47,00 & 12991,10 & 70,15 & 14074,60 & 136,49 & 12789,40 & 109,39 \\
\hline Dia 5 & 12550,20 & 0,00 & 11613,80 & 70,15 & 12796,65 & 0,00 & 11446,54 & 0,00 \\
\hline Total & 76002,84 & 47,00 & 74360,89 & 256,45 & 76890,75 & 355,69 & 73223,49 & 290,57 \\
\hline
\end{tabular}

Pode-se observar que a heurística proposta neste trabalho produziu mais estoques entre os períodos, porém não houve estoque no final do planejamento da produção. Em relação ao número de itens atrasados no final do Dia 5, as abordagens $H A_{s}$ e $H A_{c}$ atrasaram um número maior de itens em relação ao método $\mathrm{DH}$, porém menos que o obtido na prática. Já em relação à quantidade em $\mathrm{Kg}$, a heurística $H A_{c}$ foi a que menos gerou atraso.

A seguir são apresentados os resultados referentes aos itens-dias e Kg-dias em atraso e estoque entre os dias de programação, onde itens-dias (Kg-dias) são calculados multiplicando a quantidade (peso) dos itens pelo número de dias em estoque ou atraso. No 
início do período existia um atraso de 526.818 itens-dias, totalizando 426.528,53Kg-dias, e não existiam itens estocados. A Tabela 5.3 apresenta os resultados para a comparação em itens-dias e a Tabela 5.4 para Kg-dias.

Tabela 5.3: Atrasos e estoques em itens-dias.

\begin{tabular}{|c|c|c|c|c|c|c|c|c|}
\cline { 2 - 9 } \multicolumn{1}{c|}{} & \multicolumn{2}{c|}{ DH } & \multicolumn{2}{c|}{ Prática } & \multicolumn{2}{c|}{$H A_{s}$} & \multicolumn{2}{c|}{$H A_{c}$} \\
\cline { 2 - 9 } \multicolumn{1}{c|}{} & Atrasos & Estoques & Atrasos & Estoques & Atrasos & Estoques & Atrasos & Estoques \\
\hline Dia 1 & 35626 & 0 & 35698 & 46 & 33503 & 33 & 36800 & 13 \\
\hline Dia 2 & 25564 & 0 & 25324 & 23 & 22042 & 89 & 25223 & 44 \\
\hline Dia 3 & 24384 & 0 & 22710 & 1 & 21373 & 47 & 16718 & 28 \\
\hline Dia 4 & 6708 & 22 & 24964 & 2 & 18224 & 101 & 14456 & 49 \\
\hline Dia 5 & 3476 & 0 & 23237 & 3 & 16963 & 0 & 11626 & 0 \\
\hline Total & 95758 & 22 & 131933 & 75 & 112105 & 270 & 104823 & 134 \\
\hline
\end{tabular}

Tabela 5.4: Atrasos e estoques em Kg-dias.

\begin{tabular}{|c|c|c|c|c|c|c|c|c|}
\cline { 2 - 9 } \multicolumn{1}{c|}{} & \multicolumn{2}{c|}{ DH } & \multicolumn{2}{c|}{ Prática } & \multicolumn{2}{c|}{$H A_{s}$} & \multicolumn{2}{c|}{$H A_{c}$} \\
\cline { 2 - 9 } \multicolumn{1}{c|}{} & Atrasos & Estoques & Atrasos & Estoques & Atrasos & Estoques & Atrasos & Estoques \\
\hline Dia 1 & 177341,90 & 0,00 & 176425,50 & 46,00 & 182170,64 & 31,20 & 180869,92 & 33,89 \\
\hline Dia 2 & 115244,07 & 0,00 & 120116,60 & 23,00 & 126206,18 & 135,69 & 139301,04 & 97,40 \\
\hline Dia 3 & 86076,73 & 0,00 & 100182,89 & 70,15 & 95192,25 & 175,70 & 114676,70 & 171,30 \\
\hline Dia 4 & 67008,79 & 47,00 & 101314,44 & 140,30 & 78761,03 & 319,69 & 82768,50 & 263,60 \\
\hline Dia 5 & 48195,80 & 0,00 & 81500,25 & 210,45 & 58470,70 & 0,00 & 76004,16 & 0,00 \\
\hline Total & 493867,29 & 47,00 & 579539,68 & 489,90 & 540800,80 & 662,28 & 593620,32 & 566,19 \\
\hline
\end{tabular}

Em itens-dias, assim como para a comparação apenas dos itens, as abordagens $H A_{s} \mathrm{e}$ $H A_{c}$ atrasaram um número maior de itens em relação ao método $\mathrm{DH}$, porém menos que o obtido na prática. Já em relação aos Kg-dias, a situação inverteu, enquanto na comparação em relação à quantidade em $\mathrm{Kg}$ o resultado obtido na prática e pela heurística $H A_{c}$ foram melhores, ao comparar Kg-dias os resultados foram piores.

Também é possível comparar outras informações e os resultados são apresentados na Tabela 5.5.

Como o principal objetivo do modelo matemático é minimizar atrasos, o método DH obteve o melhor resultado para a função objetivo, o que já era esperado de acordo com o resultado obtido na Tabela 5.4, que além de considerar a quantidade em Kg em atraso, também considera os dias em que os mesmos estão atrasados. De acordo com a coluna 
Tabela 5.5: Avaliação da solução

\begin{tabular}{|c|c|c|c|}
\cline { 2 - 4 } \multicolumn{1}{c|}{} & Função objetivo & Subutilização & Tempo \\
\hline DH & 494212,05 & 1238,25 & 10 minutos \\
\hline Prática & 131581032,00 & 231,70 & 2 dias \\
\hline$H A_{s}$ & 541116,38 & 1484,70 & 59,92 segundos \\
\hline$H A_{c}$ & 593899,38 & 134,60 & 60,20 segundos \\
\hline
\end{tabular}

subutilização, o método DH utiliza 93,1\% da capacidade, enquanto a programação manual utiliza $98,7 \%$, a heurística $H A_{s} 91,7 \%$ e a heurística $H A_{c} 99,2 \%$. Em relação ao tempo, o método DH levou 10 minutos, a programação manual levou 2 dias (aproximadamente 16 horas) e a heurística aproximadamente 1 minuto, além de não depender de nenhum software comercial.

\subsection{Considerações finais}

De acordo com as comparações realizadas, observa-se que a heurística $H A_{s}$ é a que mais se aproxima do método DH no sentido de que o principal objetivo de ambos é minimizar atrasos, o que fez com que houvesse uma quantidade maior de subutilização do forno. A diferença percentual da função objetivo entre a heurística $H A_{s}$ e o método DH $\left(\frac{H A_{s}-D H}{H A_{s}} *\right.$ 100) é de 8,66\%, indicando o bom funcionamento da heurística.

$\mathrm{Na}$ análise da programação da produção feita na prática, nota-se que houve preocupação na maximização da utilização da capacidade do forno, o que fez com que fosse dada prioridade para lotes maiores, sem priorizar o número de dias em atraso. A heurística $H A_{c}$ é a que mais se aproxima dessa política e apesar de ter obtido um número de itens em atraso no final da programação (Dia 5) maior que o método DH, obteve menor quantidade em Kg em relação a todas as outras abordagens. Além disso, em relação ao resultado obtido na prática, aproveitou melhor o forno, minimizou muito mais o atraso e o tempo de resposta foi muito menor. 


\section{Conclusões e próximos passos}

Neste trabalho foi estudado um problema de dimensionamento de lotes que envolve a produção de múltiplos itens, com capacidade limitada e possibilidade de atraso no atendimento da demanda. O problema é aplicado ao setor de fundições, logo, também é necessário que sejam definidos os períodos de produção das ligas. O objetivo é encontrar um plano de produção de ligas e itens com custo mínimo e que seja capaz de atender a demanda pelos itens sem exceder a capacidade do forno.

Este trabalho foi inspirado em (ARAUJO, 2003). O autor propôs uma heurística que apesar de obter bons resultados, possui dependência de um software comercial, o que torna sua implantação difícil em fundições de pequeno porte.

Inicialmente, fez-se o estudo do modelo proposto em (ARAUJO, 2003) para uma fundição de pequeno porte, cujo gargalo do processo produtivo é a programação do forno e o principal objetivo é a minimização do atraso no atendimento da demanda. Em seguida, foi desenvolvida uma nova abordagem baseada na decomposição do problema em dois subproblemas: o planejamento da produção das ligas e o planejamento da produção dos itens. Com esta estratégia foi possível considerar uma penalidade para antecipação de liga que não está presente no modelo proposto na literatura, proporcionando uma forma de penalizar a subutilização do forno, questão muito importante na prática. Utilizando 
um software comercial, foram realizados testes computacionais baseados em cenários e o comportamento da estratégia de decomposição se mostrou bastante eficiente.

Devido aos bons resultados apresentados, foi desenvolvida uma heurística, independente de qualquer software comercial, para a resolução dos dois subproblemas. A heurística é baseada na relaxação lagrangiana das restrições de capacidade dos subproblemas. Ao se ignorar a capacidade, os problemas se decompõem em subproblemas de dimensionamento de lotes com um único item, que são resolvidos na otimalidade por um algoritmo de programação dinâmica. A partir de uma solução infactível, uma fase de factibilização a torna factível e uma fase de melhoria realiza transferências na tentativa de minimizar o valor da função objetivo. Foram propostos aprimoramentos para a heurística e foram realizados testes para que pudessem ser avaliados o valor da função objetivo, que retrata a minimização na entrega dos pedidos e a quantidade de forno subutilizado, ou seja, o aproveitamento do forno. As abordagens aprimoradas obtiveram, em média, resultados melhores que os gerados pelo software comercial tanto em relação ao valor da função objetivo quanto em relação à quantidade de forno subutilizado, e o tempo de resposta também foi muito satisfatório: em torno de 1 minuto.

Ao final do trabalho foi apresentado um estudo de caso para avaliar o comportamento da heurística em relação ao melhor método de resolução desenvolvido até o momento para o problema e ao que foi obtido na prática. Na solução prática, notou-se uma preocupação grande na programação da fundição em maximizar a utilização da capacidade do forno, objetivo não presente no trabalho proposto na literatura e que é retratada na heurística desenvolvida pela penalidade para antecipação de liga. Conclui-se que a heurística aprimorada proposta para a abordagem com esta penalidade conseguiu balancear dois objetivos conflitantes: minimização de atraso e maximização da utilização do forno, ou seja, a solução obtida reduziu muito o atraso das peças e aproveitou o forno de forma muito eficiente, além de ser bem rápida. Outro aspecto positivo é que a heurística dá oportunidade para o programador da produção controlar o grau mínimo de utilização do forno, tornando o modelo mais flexível.

Visando a melhoria da heurística proposta neste trabalho, os próximos passos sugeridos são:

- testar formas diferentes de calcular os custos de estoque e de atraso para o Problema das Ligas; 
- adaptar a heurística para considerar o número de períodos diferentes de 3 e 5 ;

- considerar o número máximo de fornadas $(L)$ variando de acordo com o dia da programação $\left(L_{t}\right)$;

- para o Problema das ligas, aperfeiçoar a fase de melhoria para a abordagem sem penalidade para antecipação de liga e a fase de factibilização para a abordagem com penalidade;

- adaptar a heurística para considerar tempo de preparação. 


\section{Referências bibliográficas}

ABIFA (2006). Relatório anual do setor de fundição. http://www.abifa.org.br.

AGGARWAL, A. e PARK, J. K. (1993). Improved algorithms for economic lot size problems. Operations Research, 41:549-571.

ANTHONY, R. N. (1965). Planning and control systems: a framework for analysis. Harvard University Press, Cambridge. Apud em Hax and Candea.

ARAUJO, S. A. (2003). Modelos e métodos para o planejamento e programação da produção aplicado no setor de fundições. Tese de Doutorado, ICMC-USP.

ARAUJO, S. A. e ARENALES, M. N. (2000). Problema de dimensionamento de lotes monoestágio com restrição de capacidade: modelagem, método de resolução e resultados computacionais. Pesquisa Operacional, 20(2):287-306.

ARAUJO, S. A. e ARENALES, M. N. (2003). Dimensionamento de lotes e programação do forno numa fundição automatizada de porte médio. Pesquisa Operacional, 23(3):403-420.

ARAUJO, S. A. e ARENALES, M. N. (2004). Planejamento e programação da produção numa fundição cativa de grande porte. Revista Investigação Operacional, 24:197-210.

ARAujO, S. A., AREnAleS, M. N., e ClARK, A. R. (2004). Dimensionamento de lotes e programação do forno numa fundição de pequeno porte. Gestão $\mathscr{G}$ Produção, $11(2): 1-20$. 
ARAUJO, S. A., ARENALES, M. N., e CLARK, A. R. (2006a). Joint rolling-horizon schedulling of materials processing and lot-sizing with sequence-dependent setup. Aceito na Journal of Heuristics.

ARAujo, S. A., ARENAlES, M. N., e CLARK, A. R. (2006b). Lot-sizing and furnace scheduling in small market-driven foundries. Aceito na Computers $\&$ Operations Research.

AXSÄTER, S. (1980). Economic lot sizes and vehicle scheduling. European Journal of Operational Research, 4:395-398.

BAHL, H. C., RITZMAN, L. P., e GUPTA, J. N. D. (1987). Determining lot sizes and resource requirements: a review. Operations Research, 35(3):329-345.

BITRAN, G. R. e YANASSE, H. H. (1982). Computational complexity of the capacitated lot size problem. Management Science, 28:1174-1186.

BRAHIMI, N., DAUZERE-PERES, S., NAJID, N. M., e NORDLI, A. (2006). Single item lot sizing problems. European Journal of Operational Research, 168:1-16.

CASAROTTI, J. P. D. (2005). Heurísticas para o problema de dimensionamento de lotes sem capacidade e com atraso. Relatório fapesp (iniciação científica), ICMC-USP.

CONSTANTINO, K. F. (2000). A programação de ligas metálicas. Relatório fapesp (iniciação científica), ICMC-USP.

CROWDER, P. (1976). Computational improvements for subgradient optimization. Symposia Matematica, 19:357-372.

DIABY, M., BAHL, H., KARWAN, M. H., e ZIONTS, S. (1992a). Capacitated lot-sizing and scheduling by lagrangean relaxation. European Journal of Operational Research, 59:444-458.

DIABY, M., BAHL, H. C., KARWAN, M. H., e ZIONTS, S. (1992b). A lagrangean relaxation approach for very-large-scale capacitated lot-sizing. Management Science, 38:1329-1340.

DREXL, A. e KIMMS, A. (1997). Lot sizing and scheduling - survey and extensions. European Journal of Operational Research, 99:221-235. 
DUDA, J. (2005). Lot-sizing in a foundry using genetic algorithm and repair functions. Lecture Notes in Computer Science, 3448:101-111.

DUDA, J. e OSYCZKA, A. (2005). Multiple criteria lot-sizing in a foundry using evolutionary algorithms. Lecture Notes in Computer Science, 3410:651-663.

EVANS, J. R. (1985). An efficient implementation of the wagner-whitin algorithm for dynamic lot-sizing. Journal of Operations Management, 5:229-235.

FEDERGRUEN, A. e TZUR, M. (1991). A simple forward algorithm to solve general dynamic lot sizing models with $\mathrm{n}$ periods in $\mathrm{o}(n \log n)$ or o $(n)$ time. Management Science, 37:909-925.

FEDERGRUEN, A. e TZUR, M. (1993). The dynamic lot-sizing model with backlogging: a simple o $(n \log n)$ algorithm and minimal forecast horizon procedure. Naval Research Logistics, 40:459-478.

FERNANDES, F. C. F. e LEITE, R. B. (2002). Automação industrial e sistemas informatizados de gestão da produção em fundições de mercado. Gestão $\mathscr{G}$ Produção, $9(3): 313-344$.

FLORIAN, M., LENSTRA, J. K., e KAN, A. H. G. R. (1980). Deterministic production planning: algorithms and complexity. Management Science, 26:669-679.

GEOFFRION, A. M. (1974). Lagrangean relaxation for integer programming. Mathematical Programming Study, 2:82-114.

HELD, M., WOLFE, P., e CROWDER, P. (1974). Validation of subgradient optimization. Mathematical Programming, 6:62-88.

ILOG (2001). Ilog cplex 7.5 user's manual.

JOHNSON, L. A. e MONTGOMERY, D. C. (1974). Operations research in production planning, scheduling and inventory control. John Wiley \& Sons, New York.

KARIMI, B. e GHOMI, S. M. T. F. (2001). A new heuristic for clsp problem with backlogging and setup carry-over. In International Conference on Industrial Engineering - Theory, Applications and Practice, San Francisco, CA, USA. 
KARIMI, B., GHOMI, S. M. T. F., e WILSON, J. M. (2003). The capacitated lot sizing problem: a review of models and algorithms. OMEGA, 31:365-378.

KARIMI, B., GHOMI, S. M. T. F., e WILSON, J. M. (2006). A tabu search heuristic for solving the clsp with backlogging and set-up carry-over. Journal of the Operational Research Society, 57(2):140-147.

LANDMANN, R. (2005). Um modelo heurístico para a programação da produção em fundições com utilização da lógica fuzzy. Tese de Doutorado, UFSC.

LOZANO, S., LARRANETA, J., e OLIVEIRA, L. (1991). Primal dual approach to the single level capacitated lot-sizing problem. European Journal of Operational Research, 51:354-366.

MAES, J., MCCLAIN, O., e WASSENHOVE, L. N. V. (1991). Multilevel capacitated lotsizing complexity and lp-based heuristics. European Journal of Operational Research, 53:131-148.

MAES, J. e WASSENHOVE, L. N. V. (1988). Multi-item single-level capacitated dynamic lot-sizing heuristics: a general review. Journal of Operational Research Society, 39(11):991-1004.

MILLAR, H. H. e YANG, M. (1994). Lagrangian heuristics for the capacitated multi-item lot-sizing problem with backordering. International Journal of Production Economics, 34:1-15.

MORABITO, R. e ARENALES, M. N. (1992). Um exame dos problemas de corte e empacotamento. Pesquisa Operacional, 12(1):1-20.

POCHET, Y. e WOLSEY, L. A. (1988). Lot-size models with backlogging: strong formulations and cutting planes. Mathematical Programming, 40:317-335.

SANTOS-MEZA, E., SANTOS, M. O., e ARENALES, M. N. (2002). A lot-sizing problem in an automated foundry. European Journal of Operational Research, 139:490-500.

SILVA, R. J. e MORABITO, R. (2004). Otimização da programação de cargas de forno em uma fábrica de fundição em aço-inox. Gestão $\mathcal{E}$ Produção, 11(1):135-151. 
TANG, L., LIU, J., RONG, A., e YANG, Z. (2001). A review of planning and scheduling systems and methods for integrated steel production. European Journal of Operational Research, 133:1-20.

TOLEDO, F. M. B. (1998). Dimensionamento de lotes em máquinas paralelas. Tese de Doutorado, DENSIS-UNICAMP.

TOLEDO, F. M. B. e ARMENTANO, V. A. (2006). A lagrangian-based heuristic for the capacitated lot-sizing problem in parallel machines. Aceito na European Journal of Operational Research.

TOLEDO, F. M. B. e SHIGUEMOTO, A. L. (2005). Lot-sizing problem with several production centers. Pesquisa Operacional, 25(3):479-492.

TRIGEIRO, W. W., THOMAS, L. J., e MACCLAIN, J. O. (1989). Capacitated lot sizing with setup times. Management Science, 35(3):353-366.

WAGELMANS, A., HOESEL, S. V., e KOLEN, A. (1992). Economic lot sizing: an $\mathrm{o}(n \log n)$ algorithm that runs in linear time in the wagner-within case. Operations Research, 40:S145-S156.

WAGNER, H. M. e WHITIN, T. M. (1958). Dynamic version of the economic lot size model. Management Science, 5:89-96.

WOLSEY, L. A. (1995). Progress with single-item lot-sizing. European Journal of Operational Research, 86:395-401.

ZANGWILL, W. I. (1969). A backlogging model and a multi-echelon model of a dynamic economic lot size production system - a network approach. Management Science, 15:506-527. 


\section{Requisitos para a heurística}

\section{desenvolvida}

Como já citado, a heurística necessita de dois arquivos de entrada: param.txt e cart.txt. O arquivo param.txt contém os parâmetros necessários para a resolução do problema e cada linha deve conter: número de dias de programação (3 ou 5), número de fornadas (30 ou 50), número de ligas diferentes presentes na carteira de pedidos, número de itens da carteira de pedidos, número máximo de fornadas em um dia de programação (10), capacidade do forno (360.0) e quantidade mínima (em Kg) de liga que deve ser fundida em cada fornada. Já o arquivo cart.txt é criado a partir de uma carteira de pedidos ordenada primeiramente pelas ligas e em ordem crescente da data de entrega dos pedidos, contendo pedidos com datas de vencimento dentro do horizonte de planejamento e excluídos os itens produzidos de ligas com demanda (em Kg) inferior a 120Kg. Este arquivo é composto por quatro colunas separadas por espaço. A primeira coluna contém a liga (representada por um número inteiro), a segunda contém o número de dias em atraso (inteiro positivo) ou número de dias que faltam para o vencimento do pedido (inteiro negativo), a terceira coluna contém a demanda para o item (número inteiro) e a última coluna contém o peso unitário do item representado por um número real com as casas decimais separadas por 
um ponto.

Como exemplo, a seguir são apresentados os arquivos de entrada param.txt e cart.txt, para o Cenário 11.
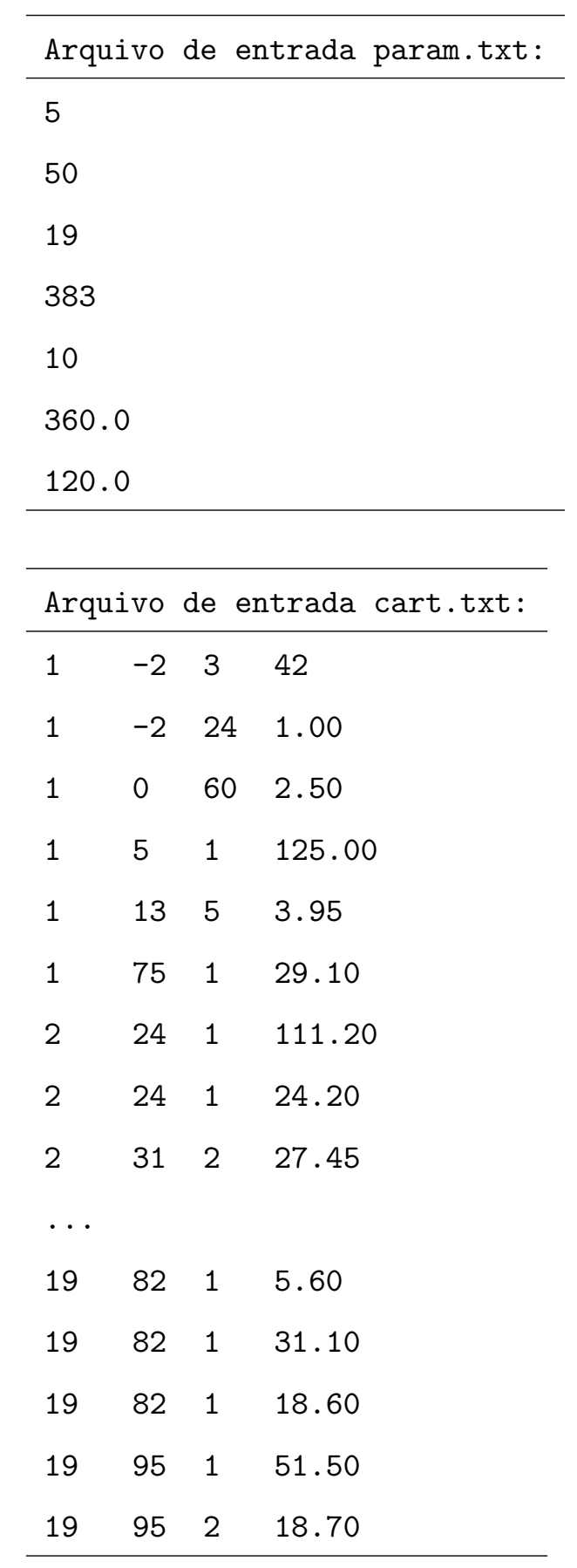

O programa gera dois arquivos de saída: liga.txt e itens.txt. O primeiro arquivo contém duas colunas que indicam respectivamente, a fornada e a liga sugerida para fusão (fornada 0 indica fim de arquivo). Já o segundo contém a programação das peças e contém quatro colunas que correspondem à fornada, à liga, ao item e à quantidade produzida, respectivamente. 
Como exemplo, a seguir são apresentados os arquivos de saída liga.txt e itens.txt.

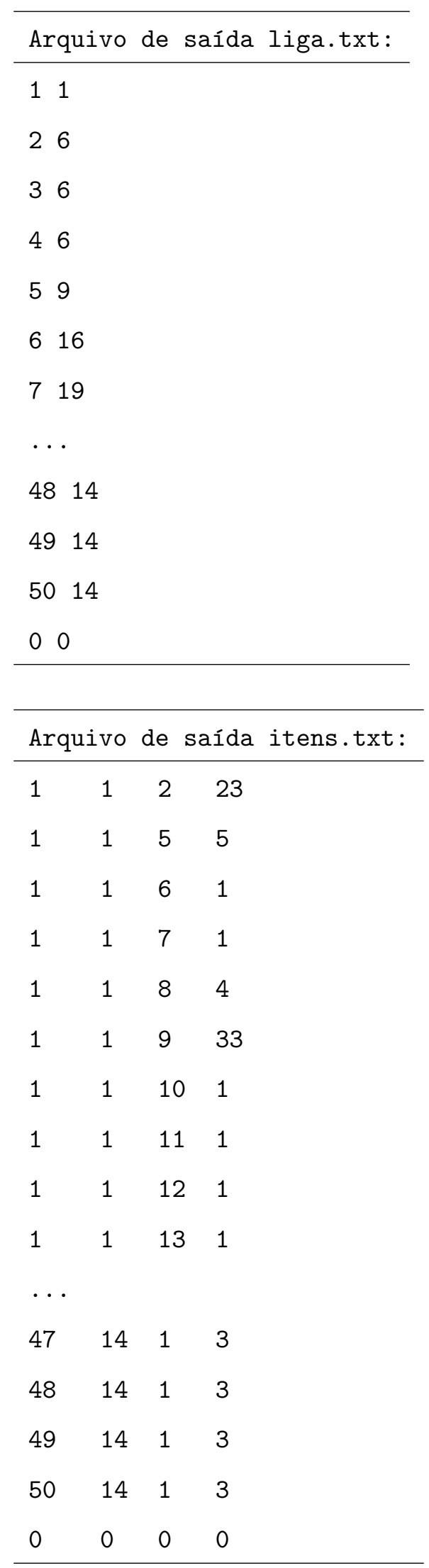

